Journal of Educational

and Psychological Sciences

Volume (6), Issue (4): 30 Jan 2022

P: $53-69$

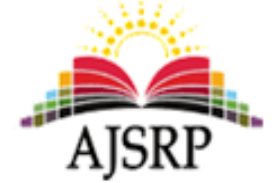

ISSN: 2522-3399

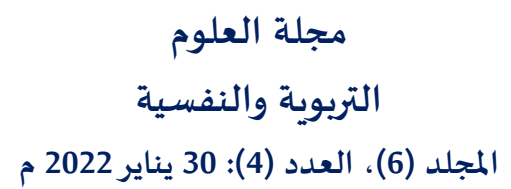

ص: 53 - 69

\title{
The Effect of Critical Thinking Strategy in Improving the Reading Skills which included in PIRLS Test from Educational Supervisors in Jerash and
}

\section{Ajloun Directorate Perspective}

\section{Raheef Mohammad Mahmud Bani Naiem \\ Ministry of Education || Jordan}

\begin{abstract}
This study aimed to identify the effect of critical thinking strategy in improving the reading skills which included in PIRLS Test from educational supervisors in Jerash and Ajloun directorate Perspective. To achieve the objectives of the study, the researcher used the descriptive quantitative analytical approach, the sample of study consisted from (70) female and male educational supervisor, it was chosen intentionally and a questionnaire for data collection; it consisted of (20) statements. The results indicated that the impact of the critical thinking strategy in improving the reading skills which included in PIRLS Test from educational supervisors in Jerash and Ajloun directorate Perspective was high with average (4.26 out of 5) and it was Positive, and there were no statistical significant differences at $(\alpha \leq 0.05)$ in the variable of sex, and directorate.
\end{abstract}

Keywords: Critical Thinking Strategy, Reading Skills, PIRLS Test, Educational Supervisor.

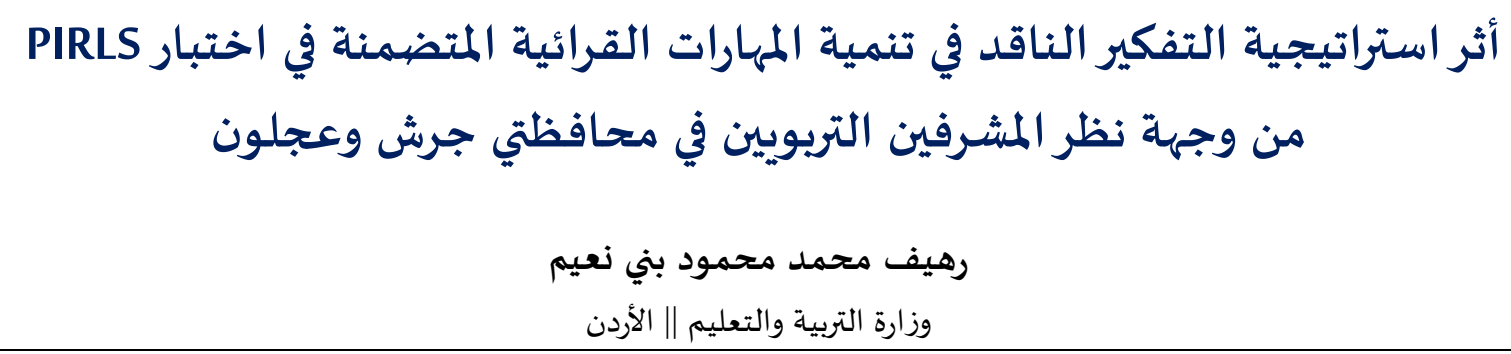

من المستخلص: هدفت الدراسة الحالية التعرف على أثر استراتيجية التفكير الناقد في تنمية المهارات القرائية المتضمنة في اختبار وجهة نظر المشرفين التربويين في محافظتي جرش وعجلون، استخدم الباحث المنهج الوصفي الكمي التحليلي، وتم إعداد استبانة (المهارات

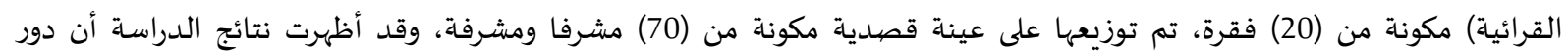

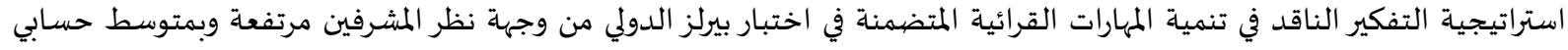

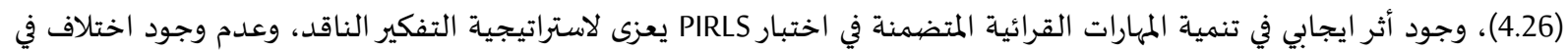

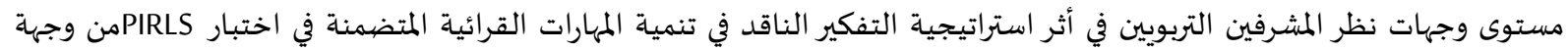
نظر المشرفين التربويين في محافظتي جرش وعجلون يعزى للجنس والمديرية. الكلمات المفتاحية: استراتيجية التفكير الناقد، المهارات القرائية، اختبار PIRLS، المشرفين التربويين. 
تؤدي اللغة دورًا مهمًا في حياة الفرد والمجتمع، فهي وسيلة اتصال الفرد مع غيره، وأداته للتعبير عن أفكاره

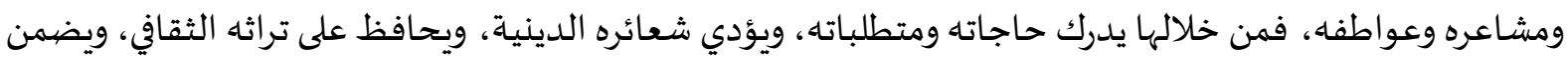

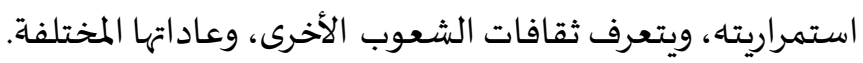
والقراءة أسلوب من أساليب النشاط الفكري، وهي عملية يراد بها إيجاد الصلة بين لغة الكالام والرموز

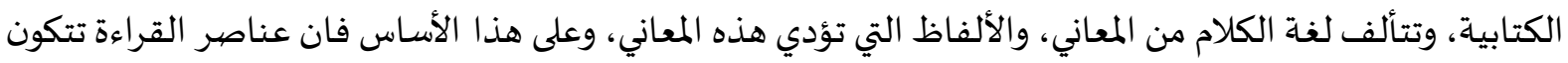

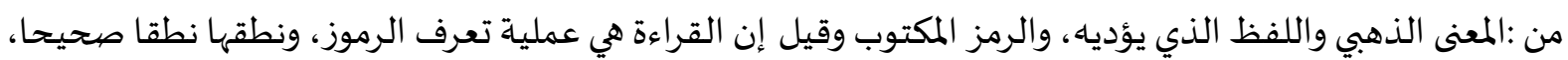

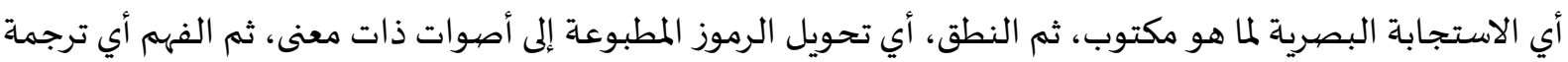

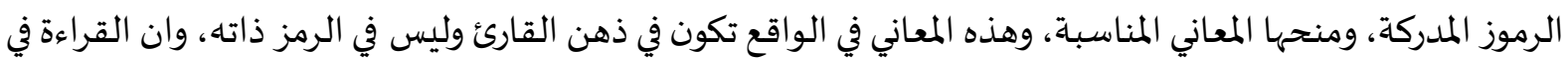

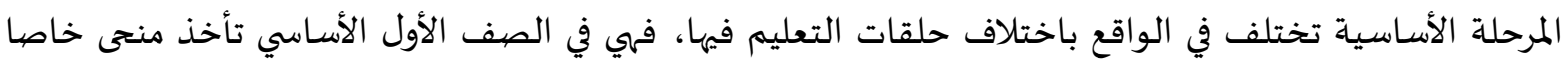

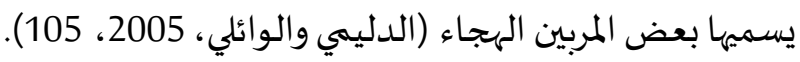

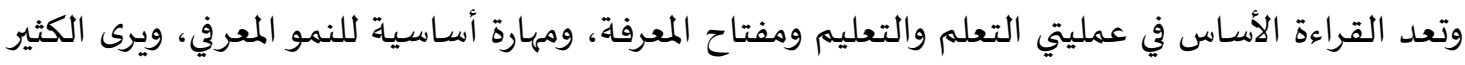

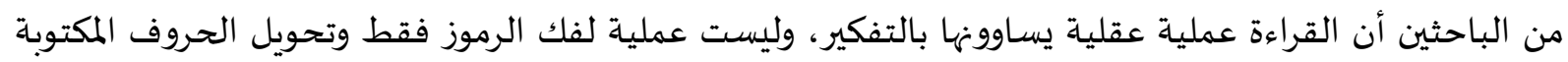
إلى أصوات، يبدو فيها القارئ بأنه يقوم بعملية آلية ليس فيها تفكير، فالقراءة الواعية الفاهمة تبين أن القارئ لا لا يقتصر على إدراك الكلمات ومعرفة الحقائق المعروضات فحسب، ولكنها يدرك أهميتها ويقف على بلى العلاقات القائمة

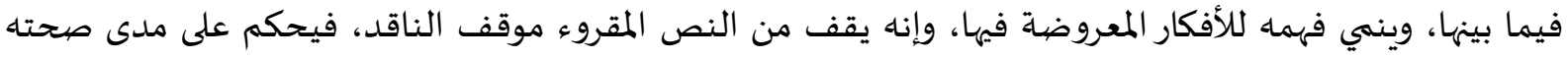
وقيمته، والأفكار الرئيسية فيه (الحوامدة، 2015).

وقد باتت الأنظمة التربوية والتعليمية في كثير من الدول تواجهاء كثيرا من المشكلات، ولعل من أهمها ضيعف

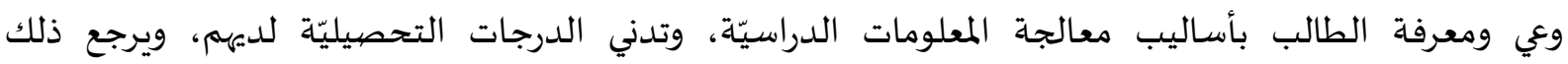
لاعتمادهم على الحفظ الآلي دون التفكير في مدى دقة المعلومات التي تقدم لهم سواء المتفوقين منهم أم غير المتفوقين (الشلاش، 2017).

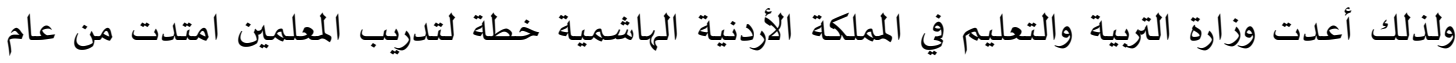

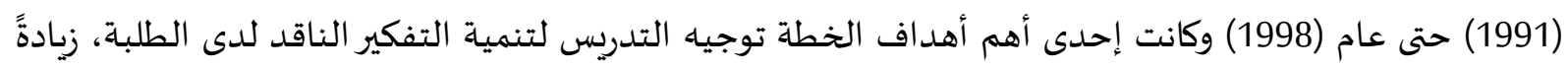
على وجود مراكز متخصصية في الأردن (مركز ديبونو للتفكير) لتخريج المعلمين والمتدربين على برامج تنمية التفكير (الحسامي، 2012).

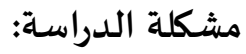
تواجه اللغة العربية اليوم صعوبات تكمن في طرائق تدريسها وتوصيلها للنشء، على الرغم من الجهود التي

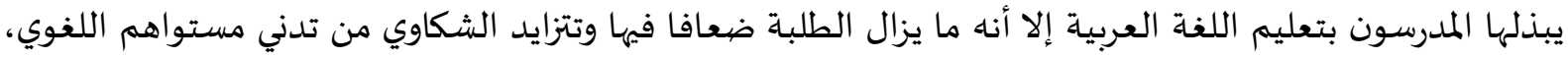

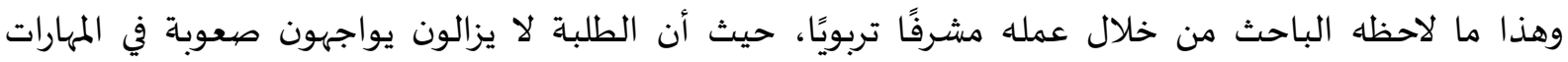
القرائية بما ينعكس سلبا على مستوى فهمهم للمواد الدراسية المختلفة وعلى تحصيلههم العلمي، مما يترتب عليه انداه

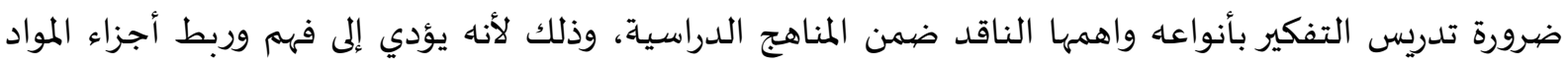
التعليمية معا، ويسهم في رفع مستوهم التحصيلي، وبناء شخصيتهم وتعزيز الاستقلالية في التفكير لديهم والموضوعية التهية.

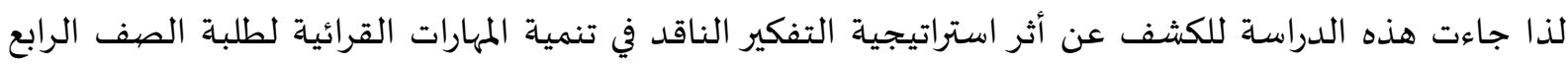
الأساسي في مادة اللغة العربية. 
أسئلة الدراسة 1- ما ما أثر استراتيجية التفكير الناقد في تنمية المهارات القرائية المتضمنة في اختبار PIRLS وجهة نظر المشرفين

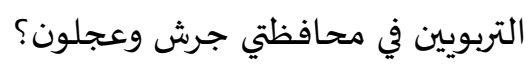
2- هل توجد فروق ذات دلالة إحصائية عند مستوى (ل0.05) في أثر استراتيجية التفكير الناقد في تنمية المهارات

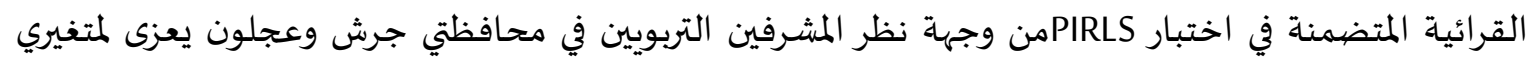

(الجنس، والمديرية)؛ (المتيه

أهداف الدراسة

تهدف الدراسة إلى الكشف عن:

1- أثر استراتيجية التفكير الناقد في تنمية المهارات القرائية المطلوبة في اختبار PRILS من وجهة نظر المشرفين

التربويين في محافظتي جرش وعجلون.

2- أثر متغيرات الدراسة (الجنس، والمديرية) على فاعلية استراتيجية التفكير الناقد في تنمية المهارات القرائية المطلوبة في اختبار PRILS من وجهة نظر المشرفين التربويين.

أهمية الدراسـة

تستمد هذه الدراسة أهميتها من التوجهات الحديثة في وزارة التربية والتعليم في الأردن، والتي تركز على

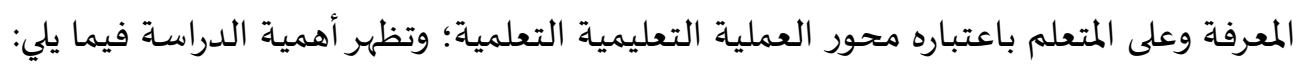

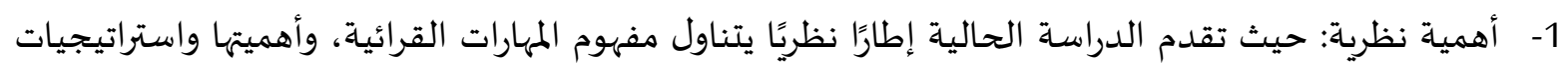
تنميتها، بالإضافة إلى تناول معلومات نظرية حول استراتيجية التفكير الناقد واهميتها في تنمية المهارات القرائية. 2- أهمية عملية: قد تفيد هذه الدراسـة:

1. مساعدة القائمين على تطوير المناهج بصورة أفضل في تحسين فلسفة الأهداف العامة للمناهج التعليمية

$$
\text { التي روعيت في وضع مناهج اللغة العربية. }
$$

2. قد تفيد معلمي اللغة العربية، وذلك من خلال زيادة وعيهم بطبيعة المهارات القرائية، وباستخدام استراتيجية

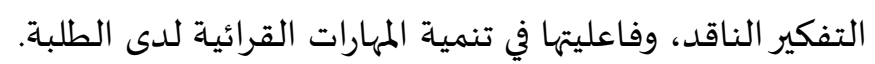

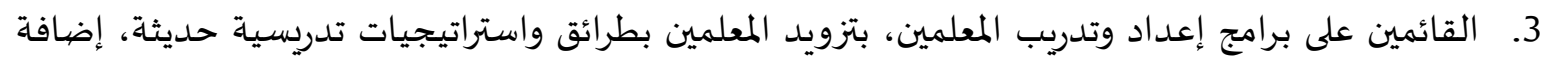

إلى أن نتائج هذه الدراسة ستفيد الجهات ذات العات الاختصاص للوقوف على على ممارسات معلمي اللغة العربية

$$
\text { ومعلماتها في تدريس المهارات القرائية. }
$$

ستقتصر الدراسة على الحدود الآتية:

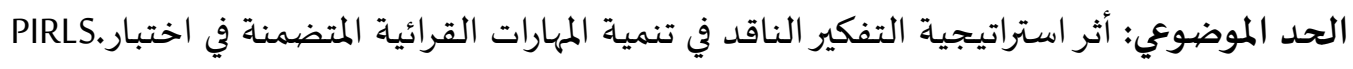

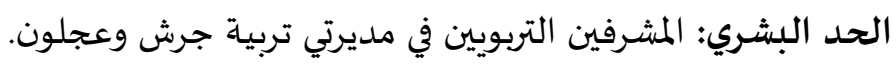

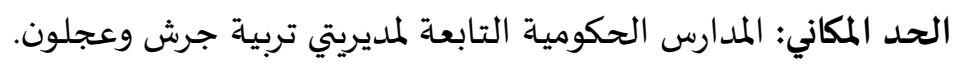

$$
\text { الحد الزماني: العام الدراسي 2021/2020. }
$$


- استراتيجية التفكير الناقد: " استراتيجية تضم مجموعة من مهارات التفكير التي يمكن أن تستخدم بصورة

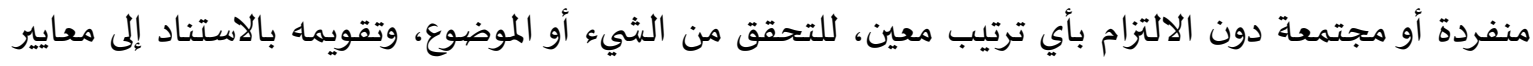

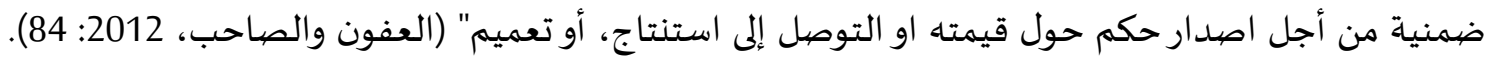

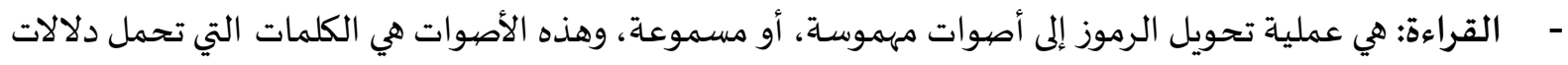

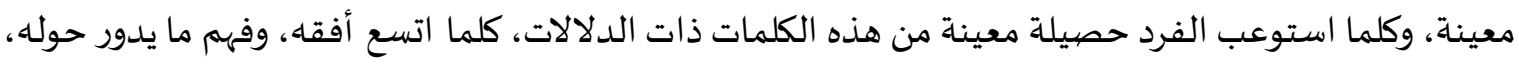

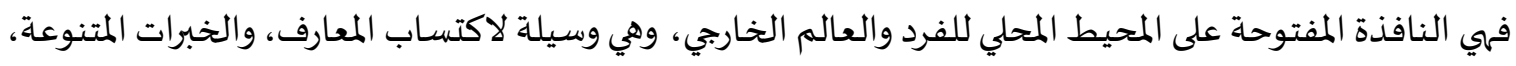

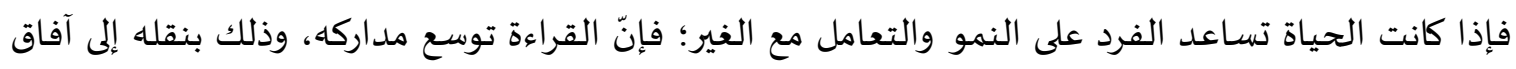
واسعة (إسماعيل، 1999). O وعرف الباحث المهارات القرائية إجرائيا بأهها: قدرة طلاب الصف الرابع الأساسي بمدارس محافظتي جرش

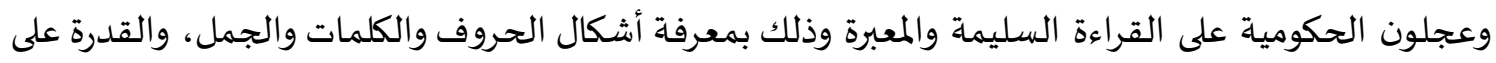

تمييز الكلمات ولفظها بصيورة صحيحة. - اختبار الدراسة الدولية PIRLS: هي دراسة دولية عالية تشرف عليها الجمعية الدولية لتقييم التحصيل التربوي

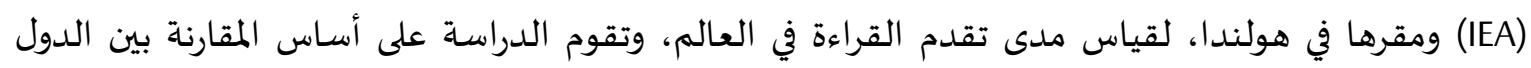

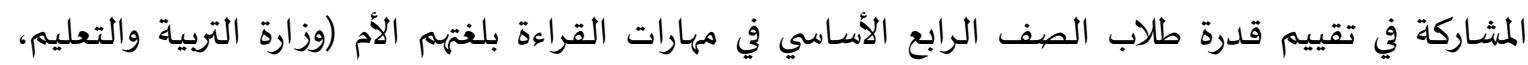

2- 2 - الإطار النظري والدراسـات السابقة.

أولاًَ- الإطار النظري:

تعتبر القراءة من أهم المهارات الدراسية التي تعلم في المرحلة الابتدائية، فهي الجسر الموصل إلى المعارف

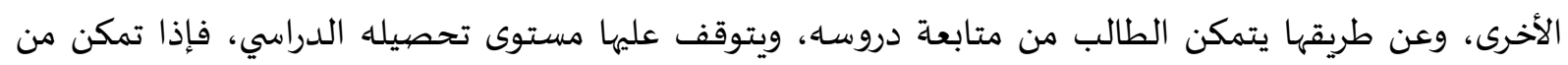

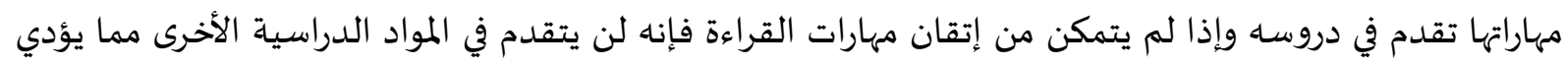

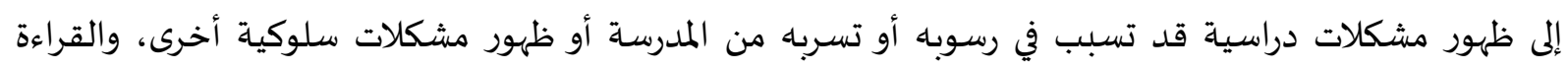

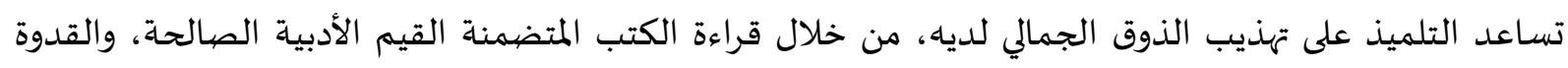

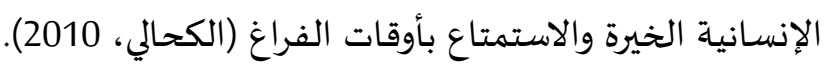

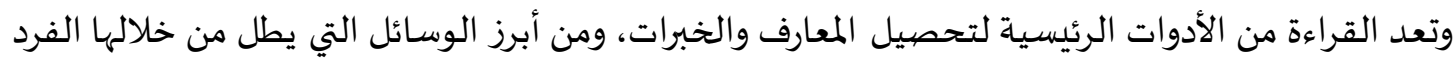

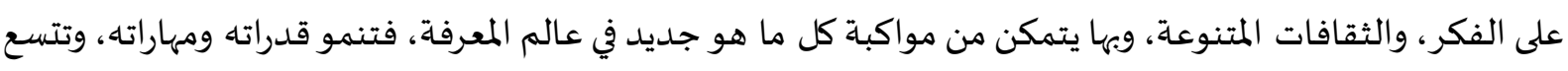

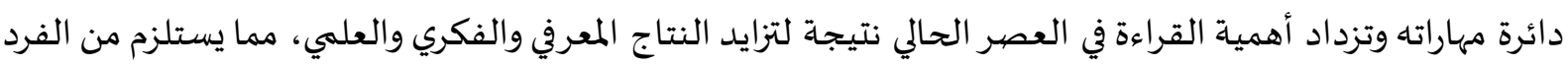

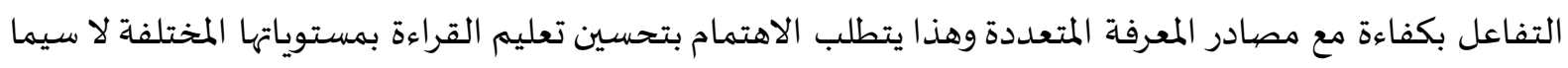
المستويات المتقدمة بما تتضمنه من وعي وتحليل ونقد وتقويم، وتكتسب إجادة مهارات القراءة بمستوياتها المتنوعة

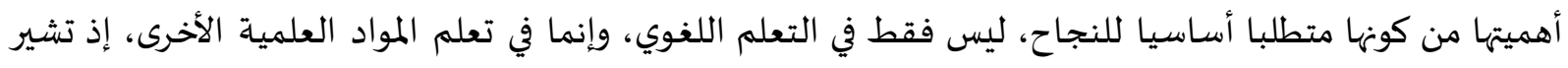
البحوث والدراسات إلى أنّ جزءا كبيرا من أسباب اخفاق الطلاب في تعلم اللغة ومهاراتها وفهم المسائل الرياضية المهاية

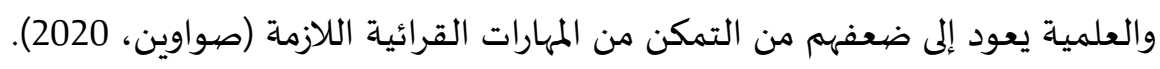


يمكن أن يكون فهم القراءة أمرا صعبا للطلاب، ويوجد عددا من المهارات الأساسية لا بد للطالب من

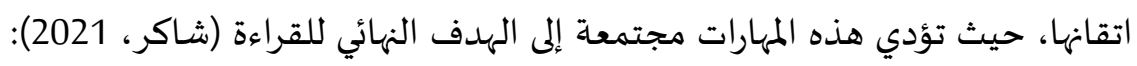

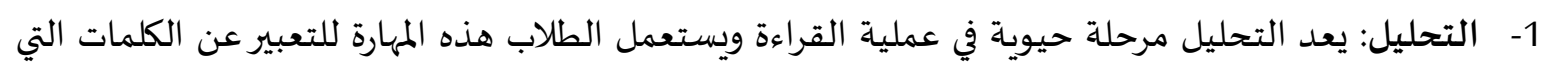
تم سماعها قبل ذلك ولكنهم لم يشاهدوها مكتوبة، ويعتمد التحليل على مهارة لغوية مبكرة يطلق عليها

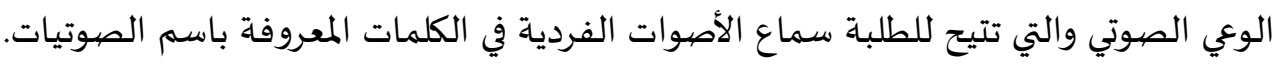

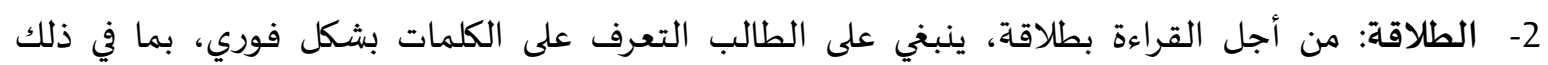

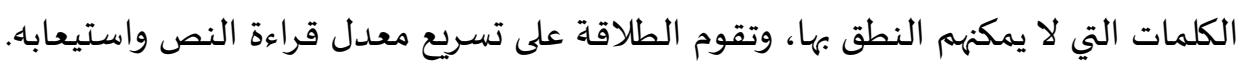

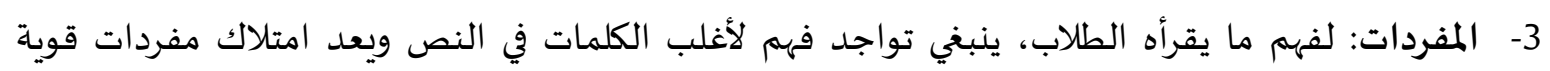

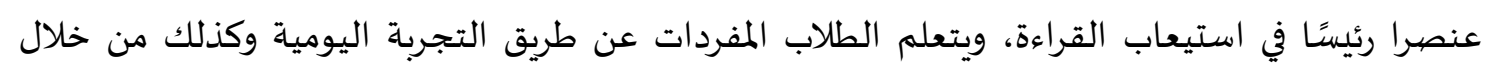

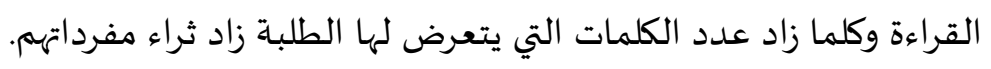
4- بناء الجمل وتماسكها: قد يظهر استيعاب كيفية بناء الجملة بصورة مهارات كتابية، لذا يتم دمج الأفكار

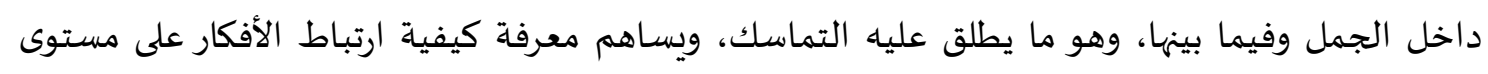
الجملة الطلاب في الحصول على معنى من مقاطع ونصيوص كاملة.

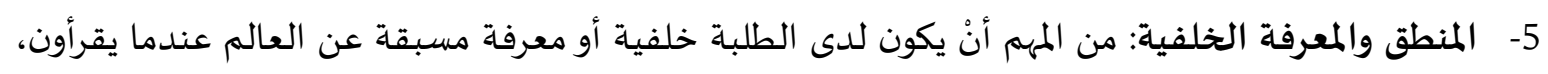

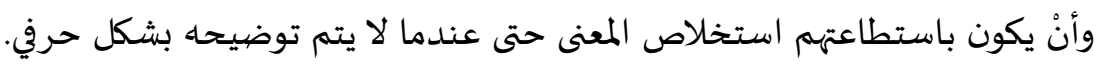

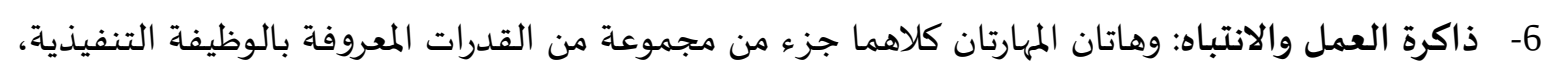

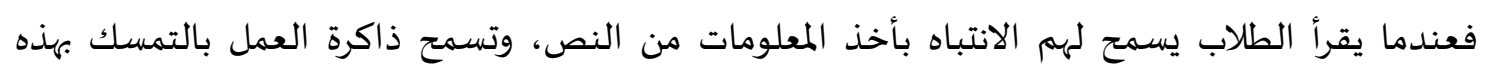

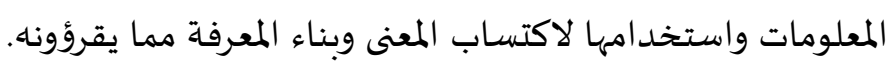

مشكلات الضعف القرائي: تؤدي الصعوبات والمشكلات في القراءة إلى فشل في كثير من الجوانب الأخرى في المنهاج، بما فيها الرياضيات،

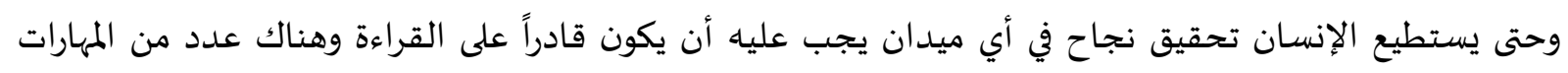

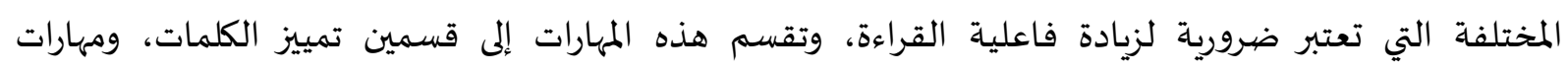

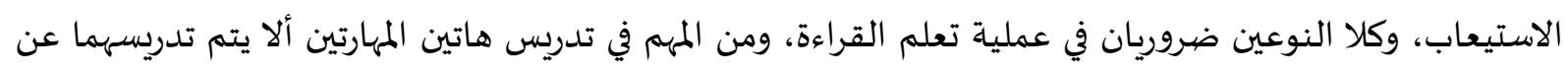

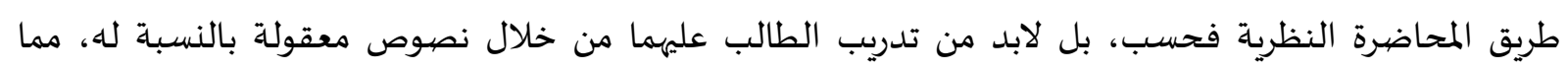

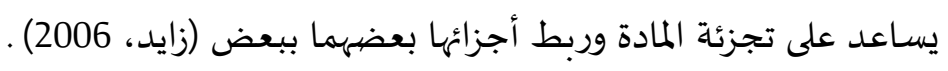

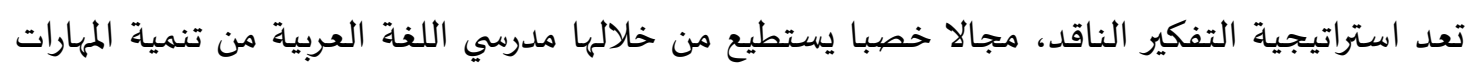

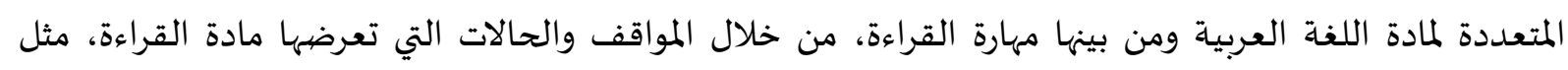

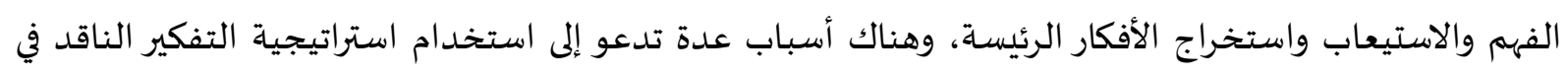
المدارس وتدريب الطلبة عليها منها (حميد، 2017):

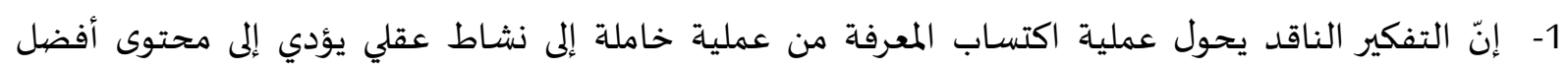

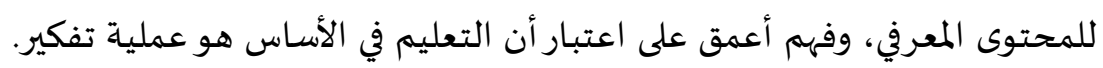

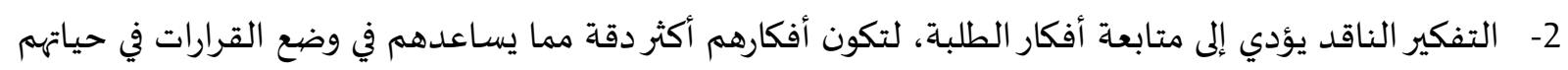

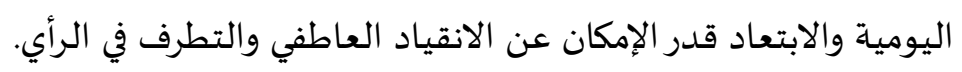


3- يعد التفكير الناقد من المقومات الأساسية للمواطنة الفاعلة في عصر اتسعت فياء المعلومات وانتشرت وسائل الإعلان لذا لا بد أن يكون الفرد قادرا على التفكير الناقد كي يستطيع الحكم على مصديداقية المعلومات المقدمة الماته

إلياه وتصنيفها.

تعتبر طرق التدريس المتبعة في المدارس والتي تعتمد على التلقين وليس التفكير من المعوقات التي تواجه

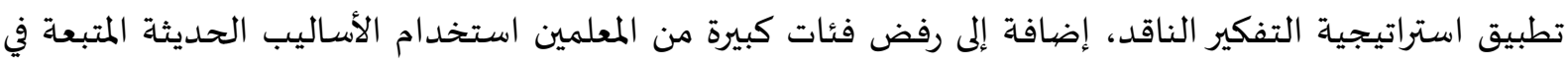

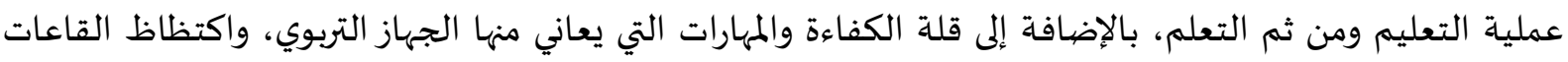

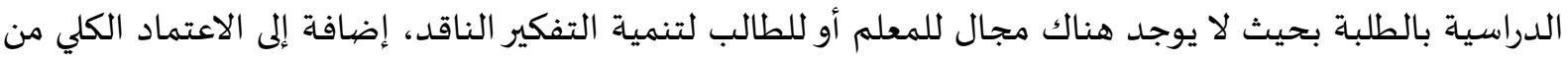

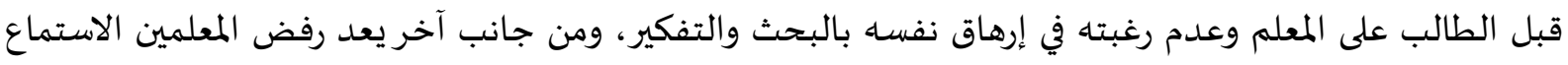

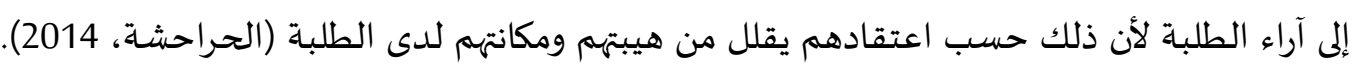

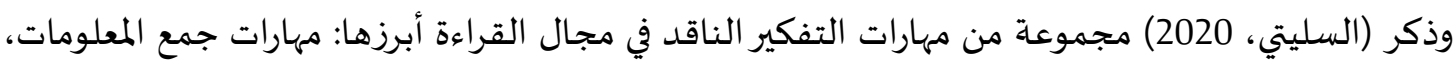

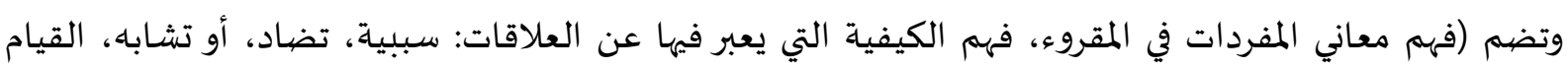

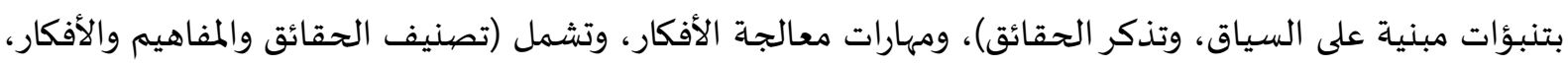

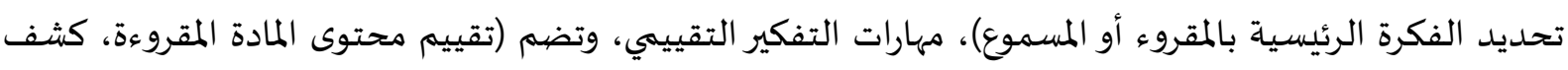
مواضيع التحيز أو الدعاية فيها). وقد قام العديد من التربويين باقتراح مجموعة من استراتيجيات التفكير الناقد والتي تساعد على تنمية التهاية مهارات التفكير الناقد ومن هذه الاستراتيجيات:

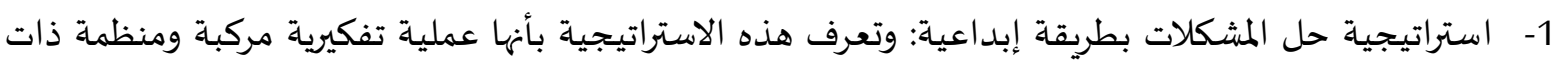

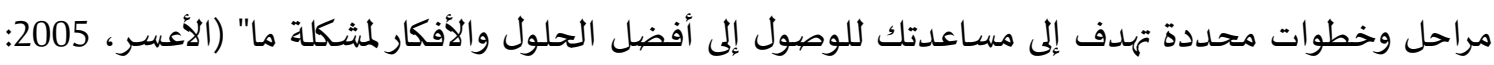

2- استراتيجية التدريس بالأقران: إن استراتيجية التدريس بالأقران تعتبر إحدى الاستراتيجيات التدريسية الهامة

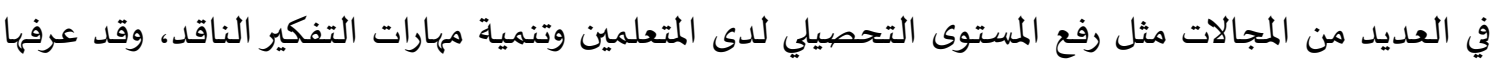

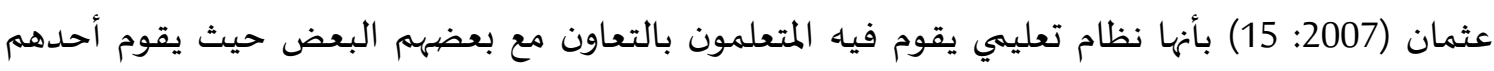
بنقل المعارف والخبرات العلمية والعملية التي يتقنها للآخرين".

تصنيف بلوم للتفكير الناقد:

يأتي التفكير الناقد في قمة هرم بلوم وهو يعتبر وفق هذا التصنيف ألتافي أرقى أنواع التفكيروهو يمثل القدرة على

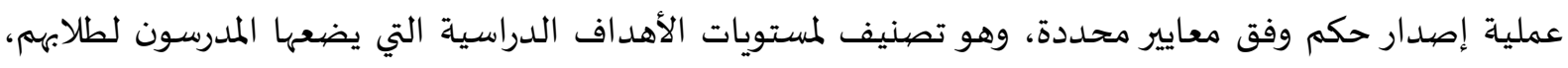

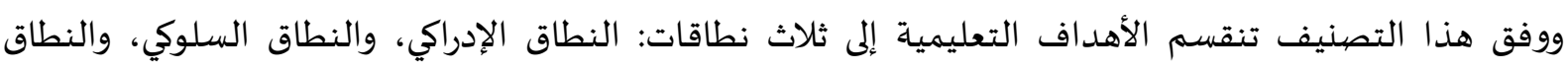
الحركي السلوكي، وكان هدف بلوم من طرح هذا التصنيف تشجيع المدرسين على التركيز على النطاقات الثلاثة من

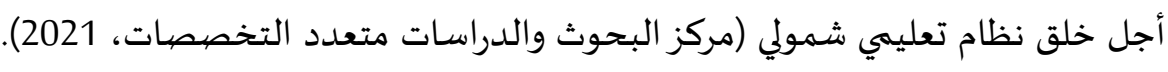
وتتمثل أهمية التفكير الناقد في العملية التعليمية بـ (الحسامي، لعركية 2012):

$$
\text { 2- - ت ترفع من المستوى التحصيلي للمتعلم. }
$$

3- تجعل المتعلم أكثر إيجابية وتفاعلا ومشاركة في عملية التعلم.

4- تزيد من ثقة المتعلم في نفساه وترفع من مستوى تقديره لذاتها 


$$
\text { 5- تشجع روح التساؤل والبحث وعدم التسليم بالحقائق. }
$$

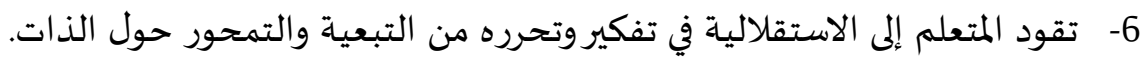

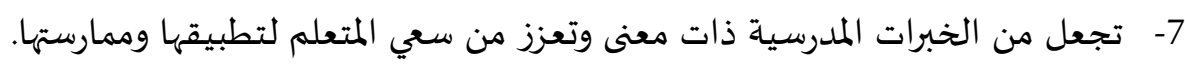

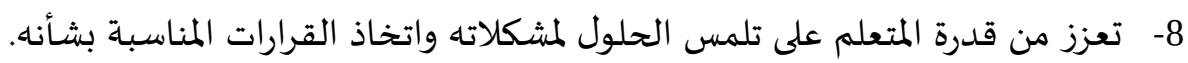

اختبار مدى التقدم في القراءة والكتابة الدولي (PIRLS):

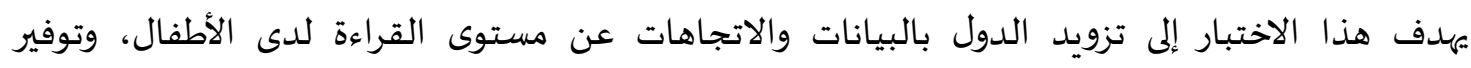

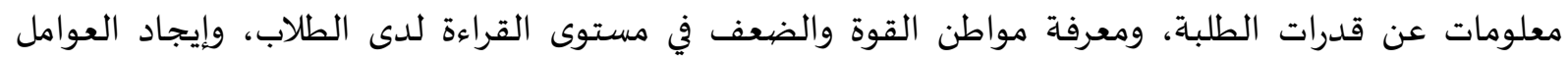
المتعلقة باكتساب المعرفة، وقد تم اختيار هذا المستوى الدراسي لانه نقطة تحول هامة في فئ نمو الطفل كقارئ، وقد الد

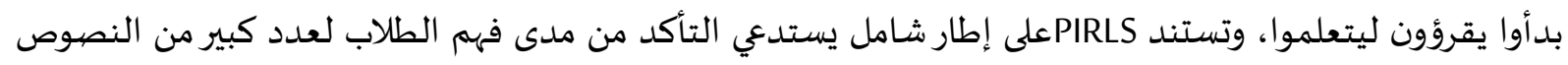

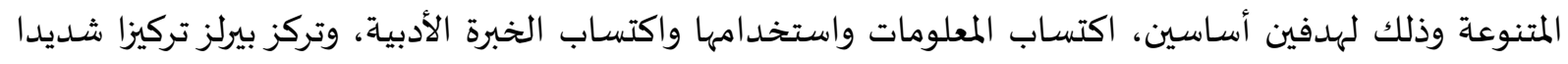

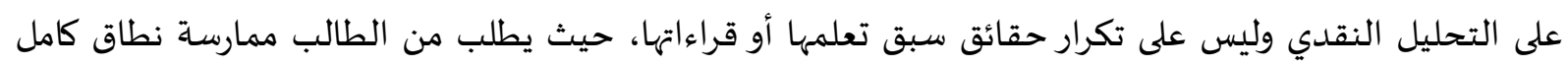

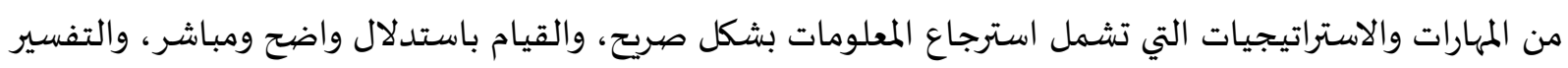

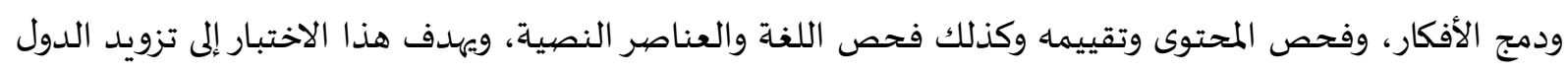

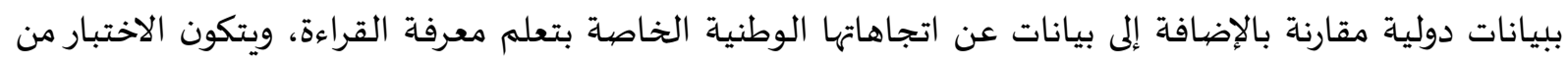

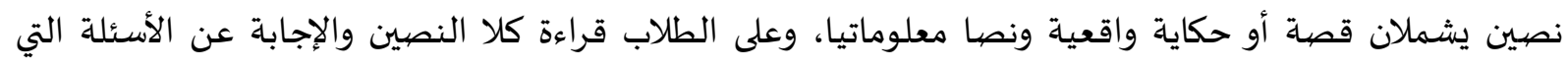

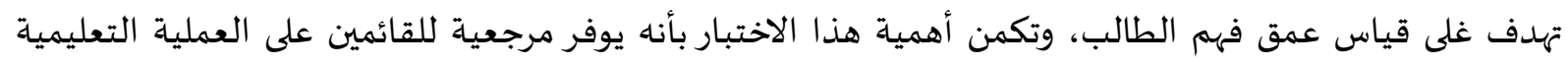

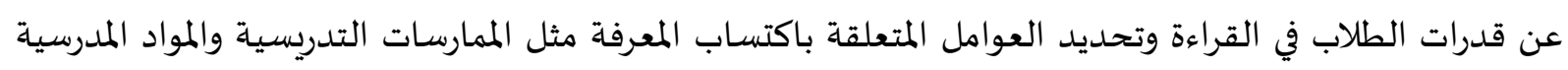
(وزارة التربية والتعليم، 2021).

ثانياً - الدراسـات السابقة: - - هدفت دراسة دوركان (Durkan, 2011) تحليل أثر تقنيات القراءة والتعبير التعاونية والأساليب التربوية

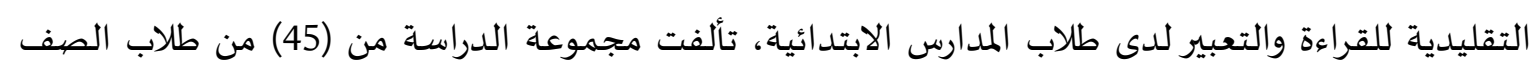

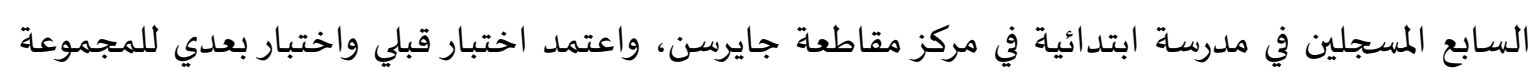

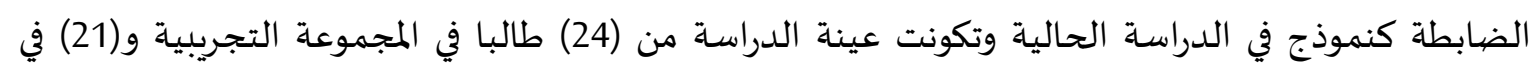

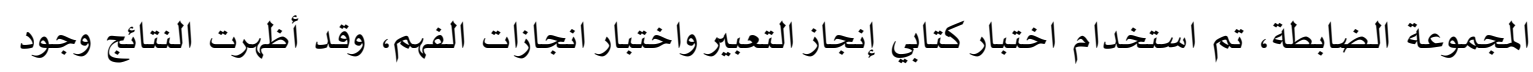

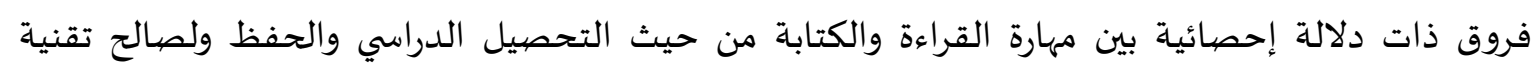
القراءة المتكاملة التعاونية. هدفت دراسة ديسانتيس (Desantis, 2011) إلى الكشف عن أثر استراتيجية التفكير البصري (VTS) في تنمية

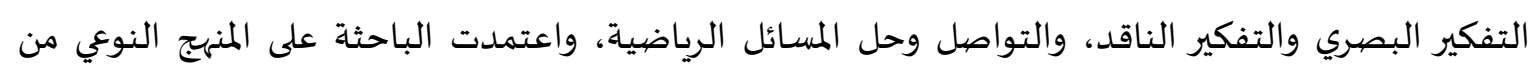

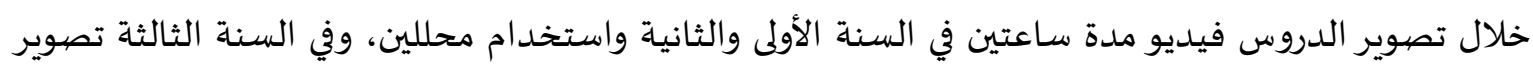

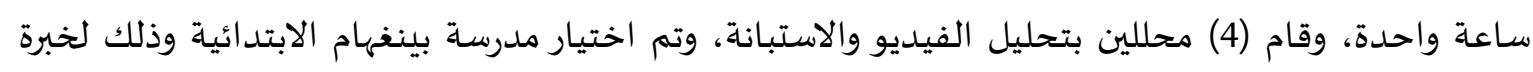

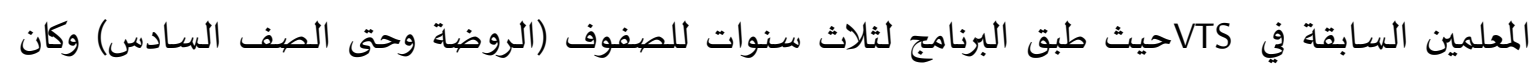

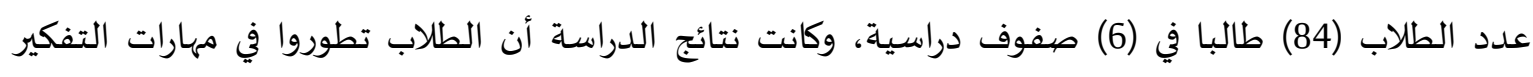

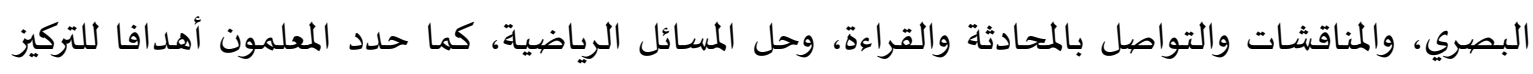
على زيادة الربط والتأطير لتعليقات الطلاب. 
هدفت دراسة الحوامدة (2015) الكشف عن فاعلية استراتيجية تعليم التفكير في تنمية مهارات القراءة الناقدة لدى طلبة الصف الخامس الأساسي في محافظة إربد، تكونت عينة الدراسة من (109) طالبا وطالبة تم تقسيمها إلى مجموعتين تجريبية مكونة من (28) طالبا وطالبة درسوا باستخدام استراتيجية تعليم التفكير، ومجموعاة إندانة

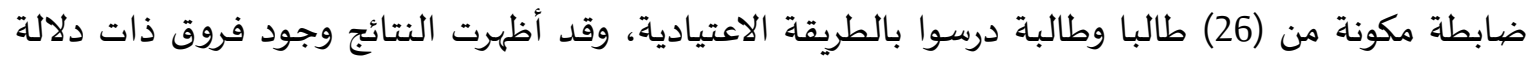

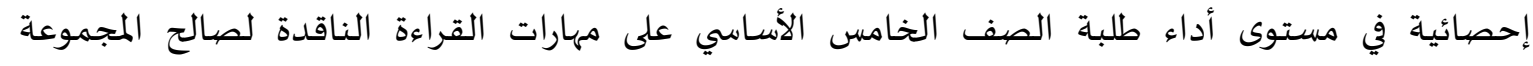

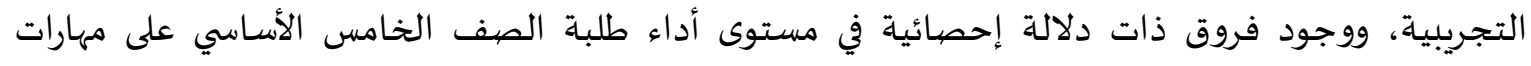

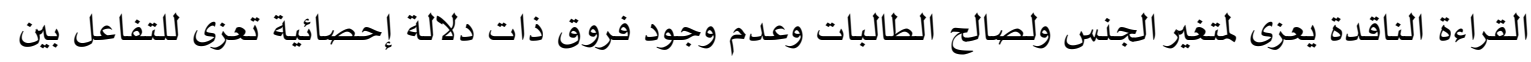

الطريقة والجنس.

هدفت دراسة (دواغرة وقبلان، 2016) التعرف على الأثر الذي تسهم باه البرامج التدريبية التي تعقدها وزارة

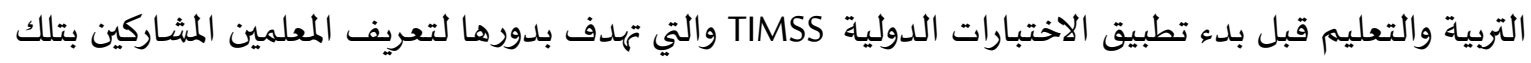

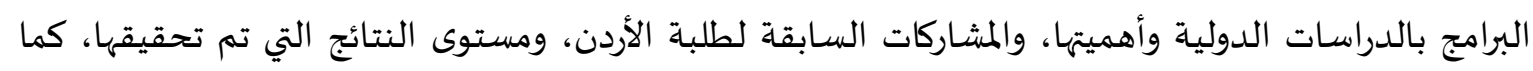

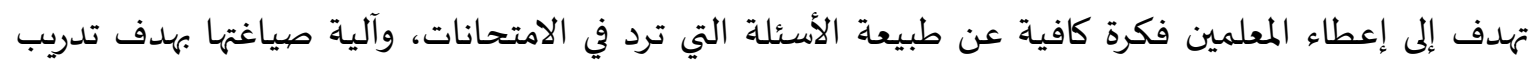

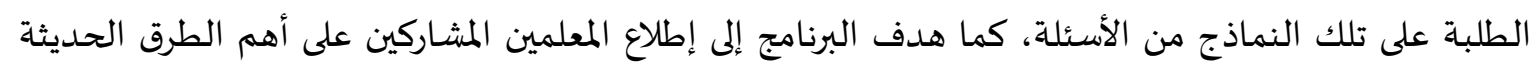
في تدريس العلوم، واستخدام استراتيجيات التدريس المعتمدة على الاستقصاء واستخدام مهارات التفكير العليا

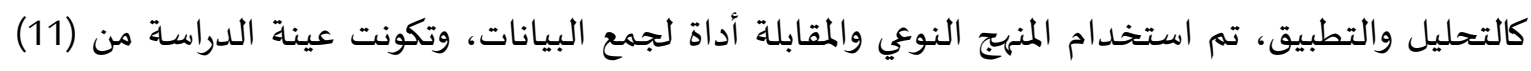

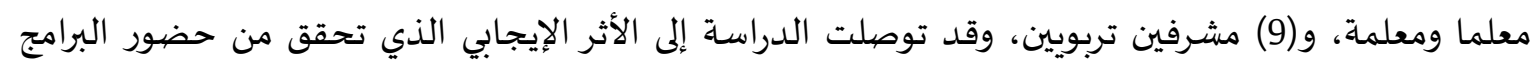

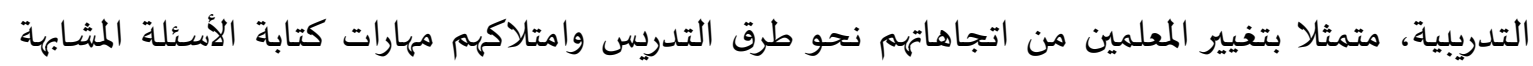
لأسئلة الاختبارات الدولية. هدفت دراسة إندا (Indah, 2018) معرفة أثر استراتيجية K.W.L على مهارة قراءة طلاب الصف الثامن،

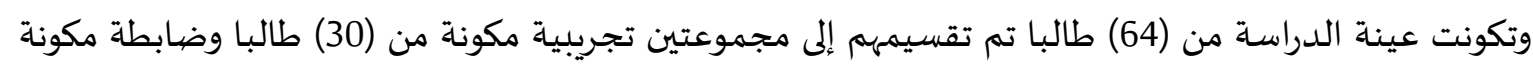

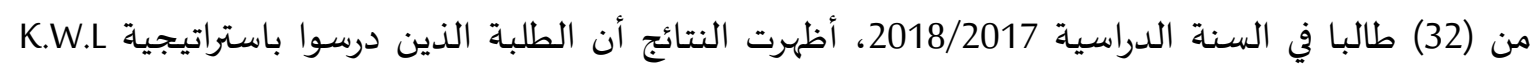
كانت مهاراتهم القرائية أفضل من الطلاب الذين درسوا بدونها.

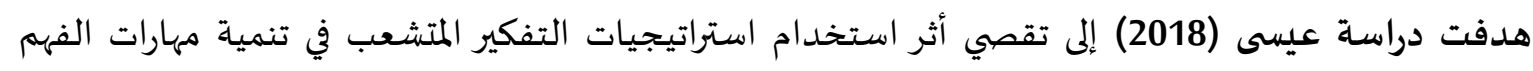

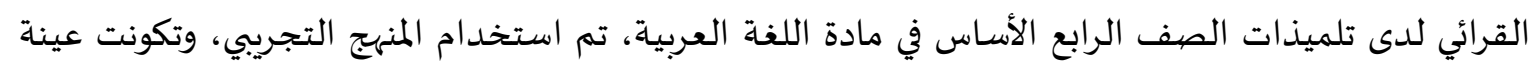

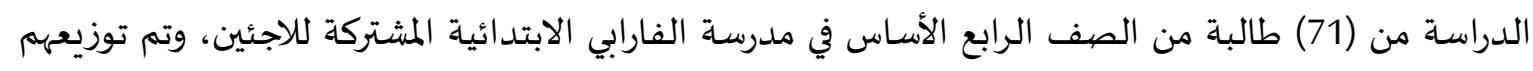
على مجموعتين تجريبية (37)، وضابطة (34) تلميذه، وتم استخدام اختبار مهارات الفهم القرائي، ودليل المعلم

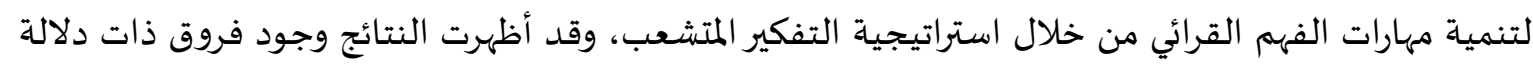

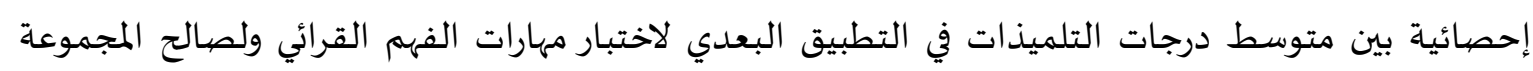

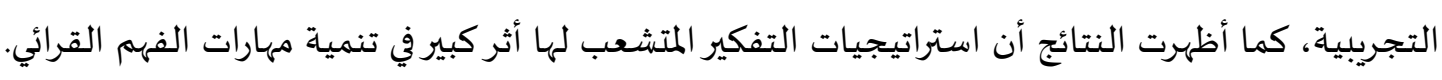

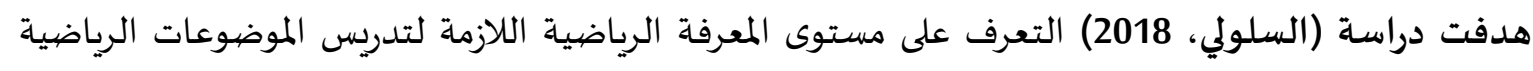

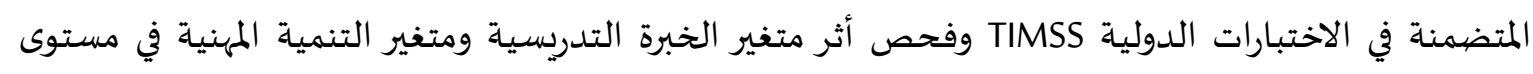

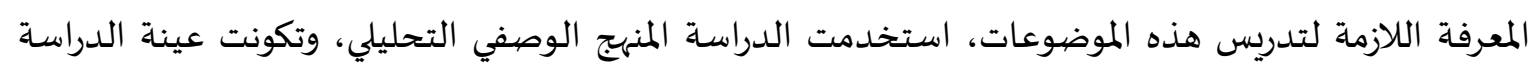

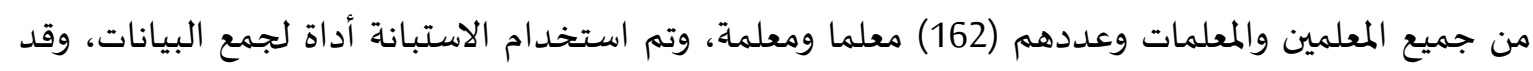

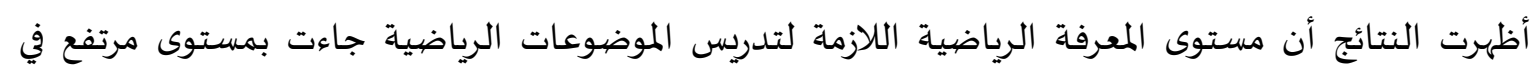
جميع المحاور الأعاد والجبر والهندسة والإحصاء والاحتمالات، كما جاءت المعلاقة الماتهبة الارتباطية بين متغير الخبرة 
التدريسية ومستوى المعرفة الرياضية غير دال إحصائيا، والعلاقة بين متغير التنمية المهنية ومستوى المعرفة الرياضية دال ولكنه ضعيف. هدفت دراسة علان (2019) التعرف على فاعلية استخدام القصاة الرقمية في تنمية مهارات القراءة الجوهرية لدى طلبة الصف الثاني الأساسي ودافعيتهم نحوها، واعتمدت الباحثة المنهجين الوصفي والشباء تجريبي، وتم

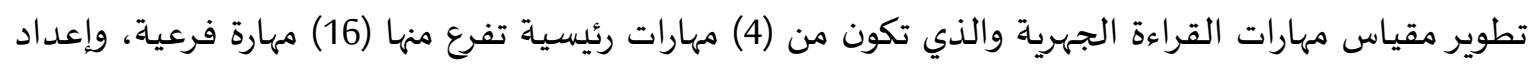

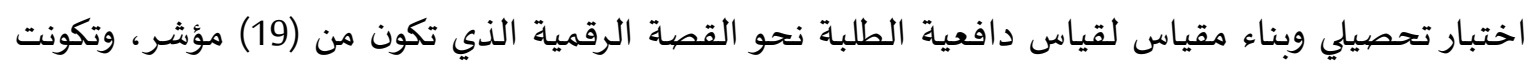

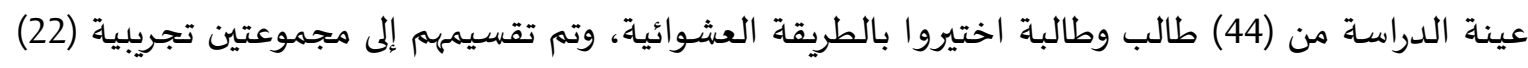

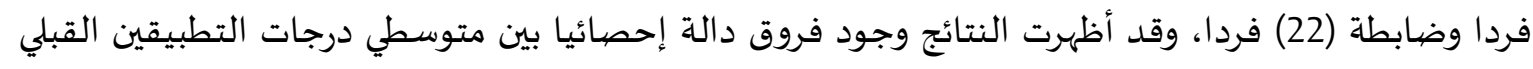

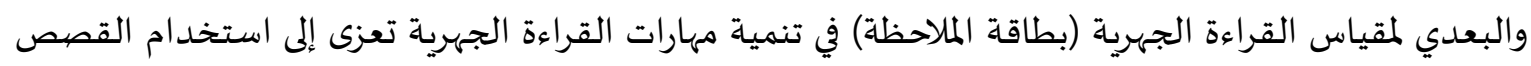

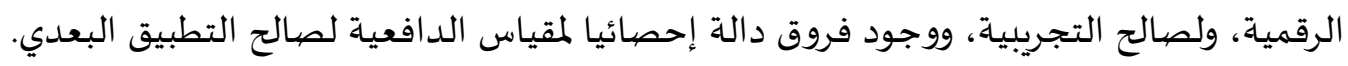

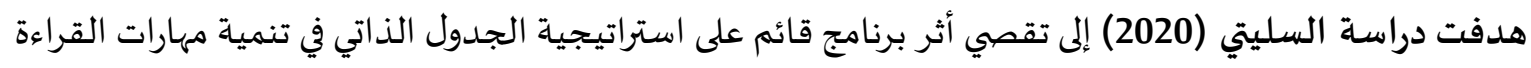

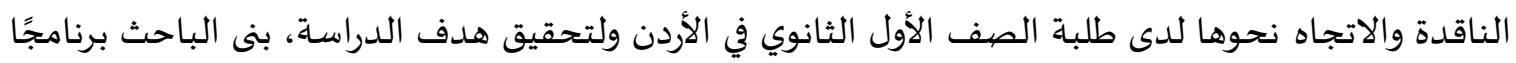

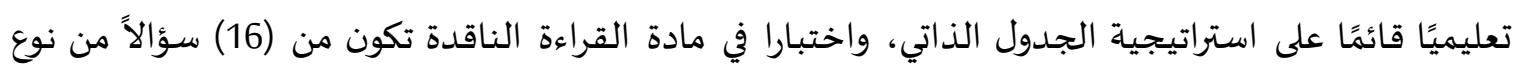

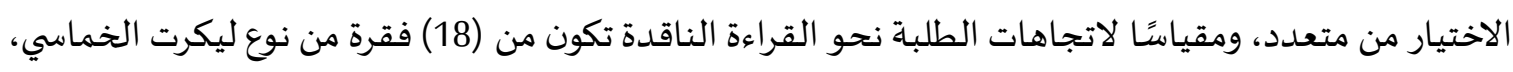

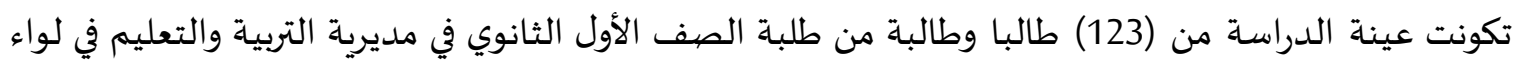

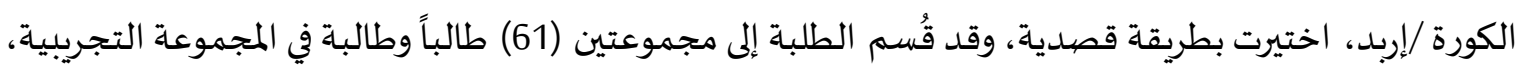

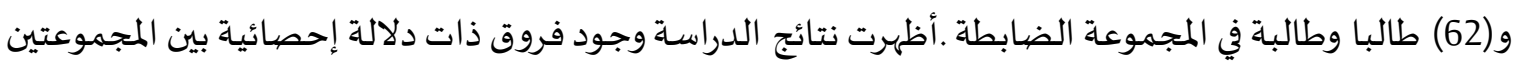

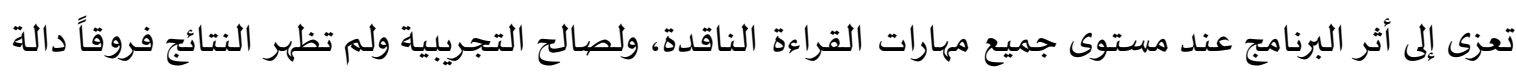

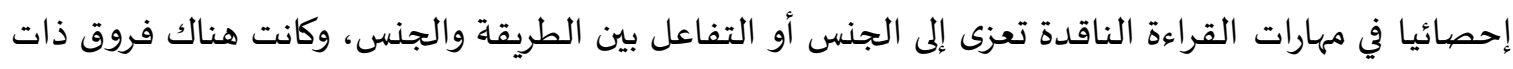

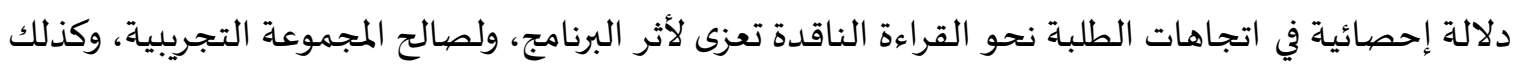

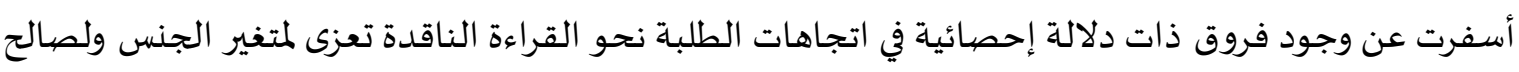

التعليق على الدراسـات السابقة: - (لمات - من خلال استعراض الدراسات السابقة العربية والأجنبية، قام الباحث ببيان أوجه الشبه والإختلاف بينن

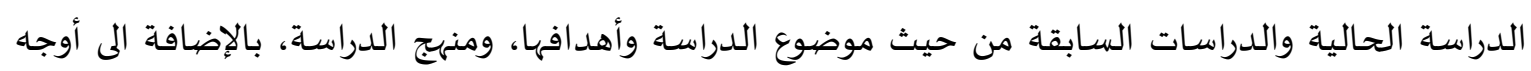

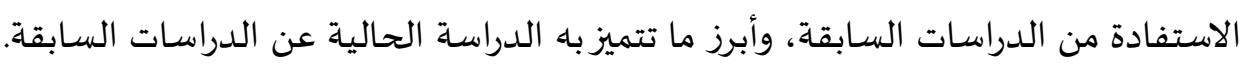

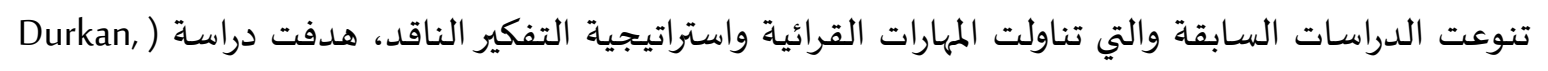

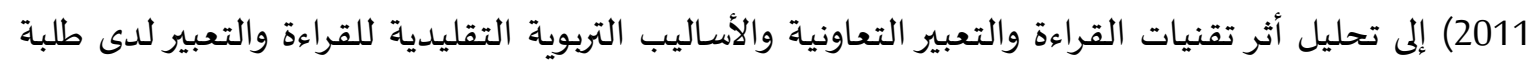

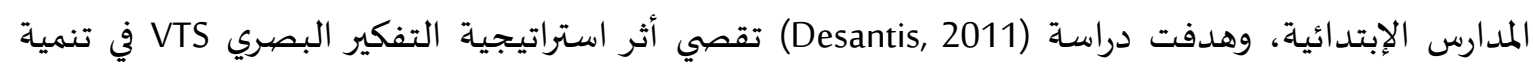

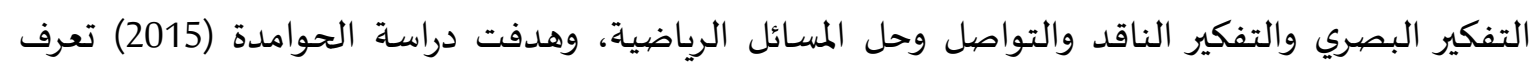

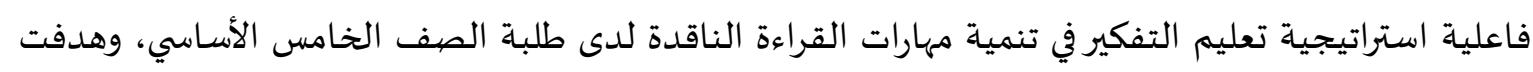

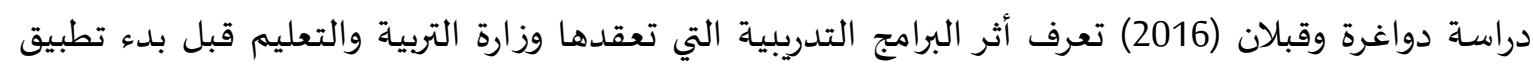

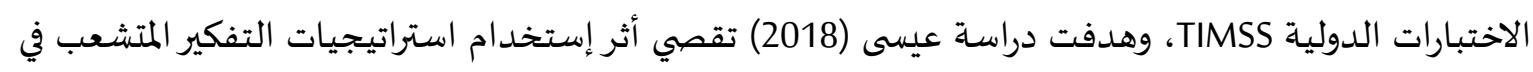

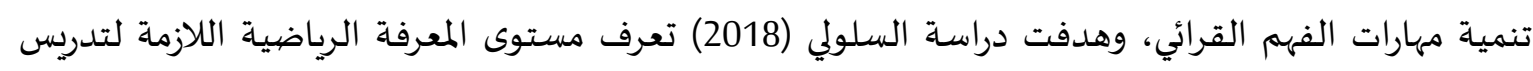


الموضيوعات الرياضية المتضمنة في الاختبارات الدولية TIMSS، وهدفت دراسة علان (2019) تعرف درجة فاعلية استخدام القصة الرقمية في تنمية مهارات القراءة الجوهرية واتجاهاتهم نحوها، وهدفت دراسية الماتهات السليتي (2020)

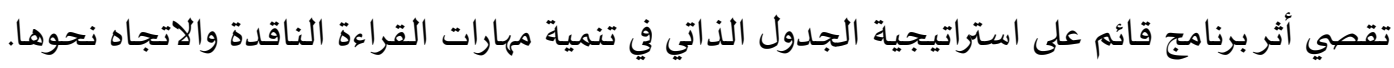

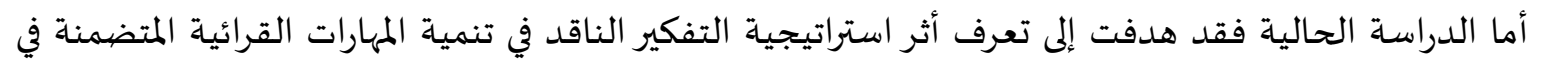

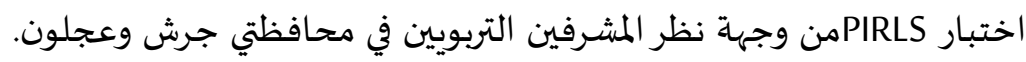

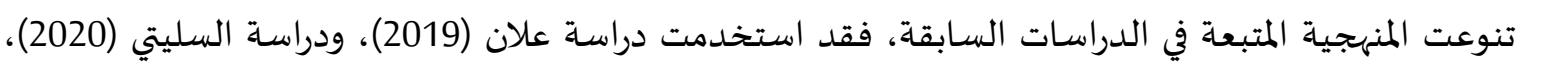

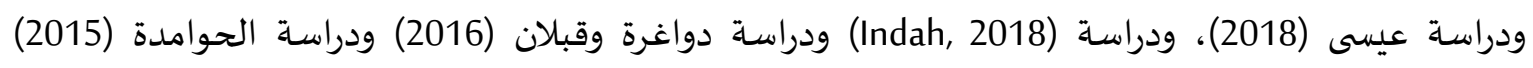

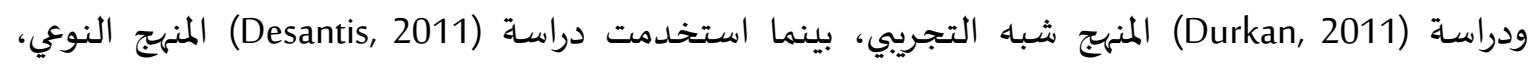
ودراسة السلولي (2018) المنهج الوصفي التحليلي، بينما استخدمت الدراسة الحالية المنهج الوصفي الكية الكية التحليلي. لقد استفاد الباحث من الدراسات السابقة في صياغة مشكلة الدراسة وإعداد أسئلتها، وكيفية تطوير أداة الدراسة واختيار عينتها، وتحديد أهم النقاط التي تناولها الإطار النظري، وفي الإجراءات الإحصائية لمعالجة البيانات.

3- منهجية الدراسـة وإجراءاتها.

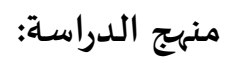
تم استخدام المنهج الوصفي الكمي التحليلي، والذي يهدف إلى تحديد أثر المتغير المستقل (استراتيجية

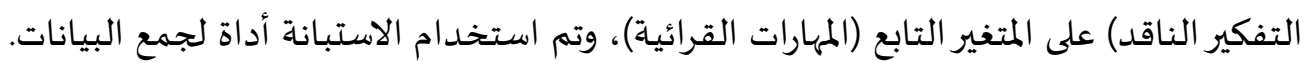

مجتمع الدراسة: تكون مجتمع الدراسة من جميع المشرفين التربويين في مديرتي تربية عجلون وجرش، في العام الدراسي 2021-2020، وبلغ عددهم (70) مشرفا ومشرفة.

عينة الدراسـة: تم اختيار عينة الدراسـة بالطريقة القصدية وذلك لصغر حجم مجتمع الدراسة، والجدول (1) يوضح توزيع أفراد عينة الدراسة تبعا لمتغير (الجنس والمديرية). الجدول (1): توزيع أفراد العينة تبعا لمتغيري الدراسة: الجنسئس والمديرية

\begin{tabular}{|c|c|c|c|}
\hline النسبة المئوية & التكرار & الفئات & المتغير \\
\hline 57.3 & 40 & مشرف & \multirow{3}{*}{ الجنس } \\
\hline 42.7 & 30 & مشرفة & \\
\hline 100.0 & 70 & المجموع & \\
\hline 40.7 & 30 & عجلون & \multirow{3}{*}{ المديرية } \\
\hline 59.3 & 40 & جرش & \\
\hline 100.0 & 70 & المجموع & \\
\hline
\end{tabular}


أداة الدراسة:

تم استخدام أداة (مقياس) المهارات القرائية (إعداد الباحث)، وتكون المقياس من (25) فقره وبعد عرضها

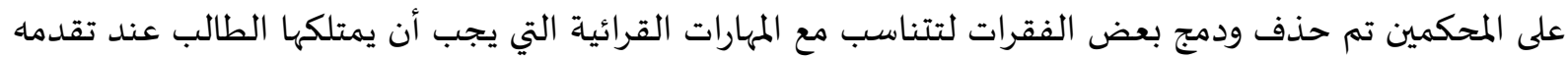
لاختبار بيرلز، ليصبح العدد النهائي لفقرات الأداة (20) فقرة.

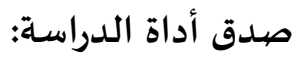
تم عرض الأداة على (5) محكمين من ذوي الخبرة والاختصاص؛ لمعرفة آرائهم حول فقرات الاستبانة، وفي

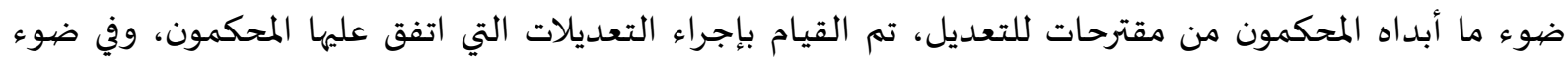
ذلك تم تعديل وحذف عددًا منها، بالإضافة إلى إعادة صياغة بعض الفقرات لتشير بشكل مباشر ومختصر لما تهدف لله الفقرة، مما حقق الصدق الظاهري. بهدف التحقق من مؤشرات صدق بناء جميع فقرات أداة الدراسـة، تم تطبيق مقياس المهارات القرائية على عينة مؤلفة من (20) مشرفا ومشرفة تربوية من خارج مجتمع الدراسة المستهدفة؛ ومن ثم تم حساب مؤشرات صدق البناء باستخراج معاملات الارتباط المصحح لعلاقة الفقرة بالمقياس لدى مشرفي العينة الاستطلاعياة، وذلك كما هو مبين في الجدول (2).

جدول (2) معاملات الارتباط بين الفقرات والدرجة الكلية لمقياس ربط المعرفة بالحياة

\begin{tabular}{|c|c|c|c|}
\hline معامل الارتباط مع الأداة & رقم الفقرة & معامل الارتباط مع الأداة & رقم الفقرة \\
\hline$* * 0.70$ & 11 & ${ }^{*} 0.60$ & 1 \\
\hline$* * 0.68$ & 12 & $* 0.60$ & 2 \\
\hline$* 0.48$ & 13 & $* 0.56$ & 3 \\
\hline$* * 0.79$ & 14 & $* 0.66$ & 4 \\
\hline$* * 0.95$ & 15 & $* * 0.73$ & 5 \\
\hline$* * 0.96$ & 16 & $* * 0.76$ & 6 \\
\hline$* * 0.72$ & 17 & $* * 0.78$ & 7 \\
\hline$* * 0.77$ & 18 & $* * 0.81$ & 8 \\
\hline$* * 0.69$ & 19 & $* * 0.87$ & 9 \\
\hline$* * 0.83$ & 20 & $* * 0.89$ & 10 \\
\hline
\end{tabular}

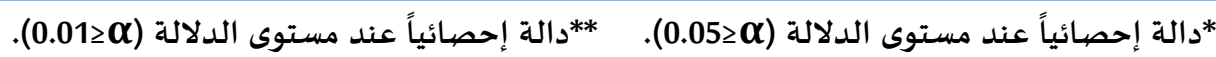

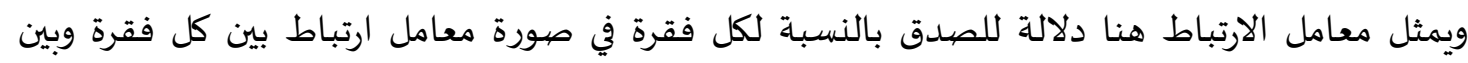

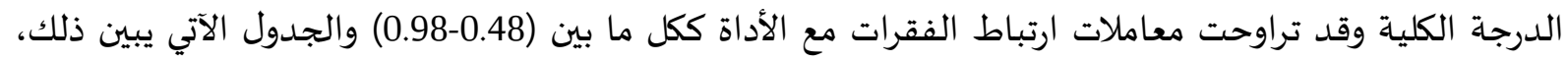

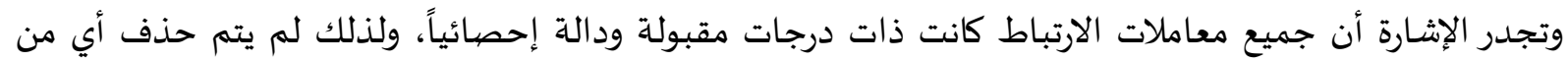
هذه الفقرات. 
للتأكد من ثبات المقياس، فقد تم التحقق بطريقة الاختبار وإعادة الاختبار (test - Re test) بتطبيق المقياس، وإعادة تطبيقه بعد أسبوعين على العينة الاستطلاعية سابقة الذكر، ومن ثم تم حساب معامل ارتباط بيرسون بين تقديراتهم في المرتين.

وتم أيضا حساب معامل الثبات بطريقة الاتساق الداخلي حسب معادلة كرونباخ ألفا، وبطريقة التجزئة النصفية حسب معادلة جوتمان، والجدول رقم (3) يبين معامل الاتساق الداخلي وفق معادلة كرونباخ ألفا والتجزئة

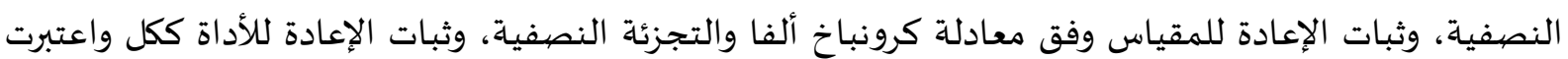
هذه القيم ملائمة لغايات هذه الدراسة.

جدول (3) معامل الاتساق الداخلي كرونباخ ألفا وثبات الإعادة والتجزئة النصفية للدرجة الكلية لمقياس المهارات القرائية

\begin{tabular}{|c|c|}
\hline القيمة & الطريقة \\
\hline 0.70 & ثبات الإعادة بيرسون \\
\hline 0.87 & الاتسـاق الداخلي كرونباخ ألفا \\
\hline 0.81 & جوتمان للتجزئة النصفية \\
\hline
\end{tabular}

ويتبين من الجدول (3) أن معاملات الثبات جيدة؛ حيث تراوحت بين (0.60-0.87) واعتبرت هذه القيم

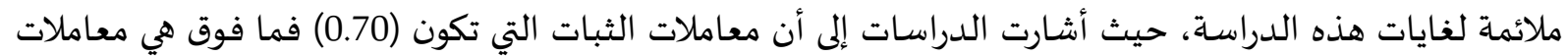

\section{تصحيح المقياس:}

اشتملت أداة قياس المهارات القرائية على (20) فقرة، حيث يجاب عليها بتدريج خماسي يشتمل البدائل (اوافق بشدة وتعطي عند تصحيح المقياس (5) درجات، اوافق وتعطي عند تصحيح المقياس (4) درجات، متردد

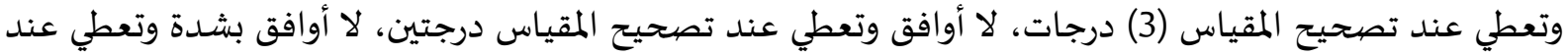

تصحيح المقياس (درجة واحدة). وقد تم تصنيف الأوساط الحسابية لاستجابات عينة الدراسة إلى ثلاثة مستويات على النحو الآتي: مرتقع ويعطى الحاصلين على درجة من (3.67-5)، ومتوسط ويعطي للحاصلين على درجة تتراوح من (2.34) وحتى (3.66)، منخفض ويعطى للحاصلين على درجة من (1-2.34). وقد تم احتساب المقياس من خلال استخدام المعادلة الآتية: الحد الأعلى للمقياس (5) - الحد الأدنى للمقياس (1)

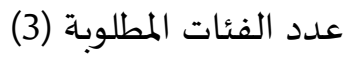

(1-5) =3 1.33 (طول الفئة) ومن ثم إضافة الجواب (1.33) إلى نهاية كل فئًة. والجدول (4) يوضح مديات المتوسطات الحسابية وذلك للإفادة منه عند التعليق على المتوسطات الحسابية.

جدول (4) مقياس تحديد مستوى الملائمة للوسط الحسابي

\begin{tabular}{|c|c|}
\hline درجة التقييم & الوسط الحسابي \\
\hline منخفضية & $2.33-1$ \\
\hline متوسطة & $3.67-2.34$ \\
\hline
\end{tabular}




\begin{tabular}{|c|c}
\hline الوسط الحسابي & 5.68 \\
\hline
\end{tabular}

\section{4- عرض النتائج ومناقشتها.}

النتائج المتعلقة بالسؤال الأول: " ما أثر استراتيجية التفكير الناقد في تنمية المهارات القرائية لدى طلبة الصف

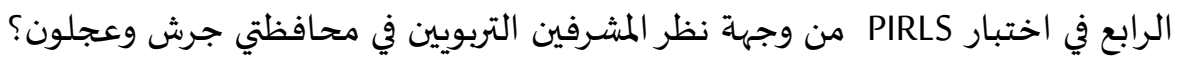

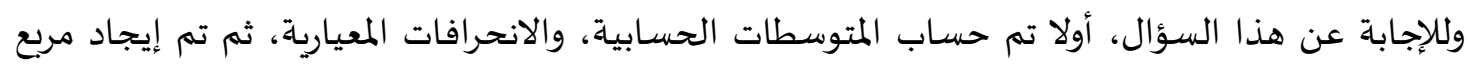

إيتا (2) لقياس حجم أثر استراتيجية التفكير الناقد في تنمية المهارات القرائية المتضمنة في اختبار

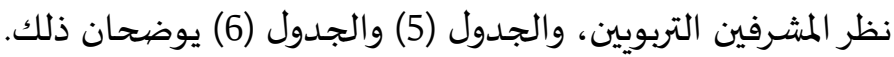

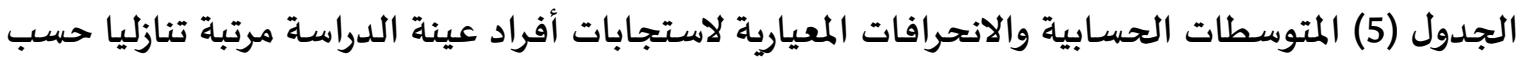

$$
\text { المتوسطات الحسابية }
$$

\begin{tabular}{|c|c|c|c|c|c|}
\hline تقبيم & 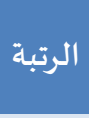 & 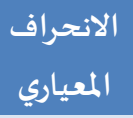 & الحتوسط الحسب & 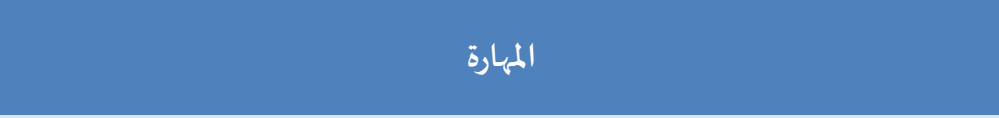 & $\hat{\imath}$ \\
\hline 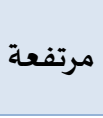 & 1 & 0.33 & 4.52 & تنمي استراتيجية التفكير الناقد مقدرة الطلبة المعرفية حول الموضيوع الذي & 8 \\
\hline 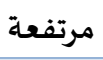 & 2 & 0.32 & 4.49 & تنمي استراتيجية التفكير الناقد مهارة استنتاج الفكرة الرئيسة من النص. & 1 \\
\hline 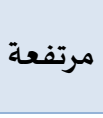 & 3 & 0.33 & 4.46 & 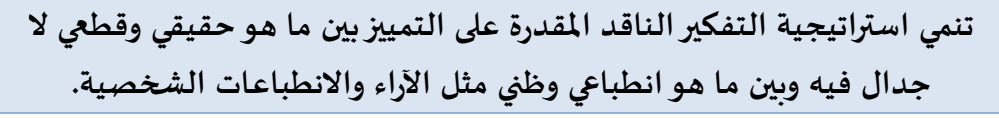 & 5 \\
\hline 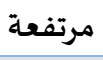 & 4 & 0.38 & 4.44 & تنمي استراتيجية التفكير الناقد مقدرة الطلاب على تحديد نوع المادة المقروءة. & 14 \\
\hline 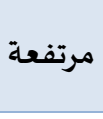 & 5 & 0.44 & 4.41 & تنمي استراتيجية التفكير الناقد مقدرة الطلاب على التحقق من الارتباطات بين & 6 \\
\hline 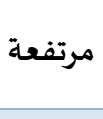 & 6 & 0.43 & 4.39 & تنمي استراتيجية التفكير الناقد مهارة تحديد المسلمات والافتراضات التي استند & 2 \\
\hline 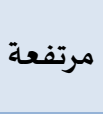 & 7 & 0.54 & 4.37 & 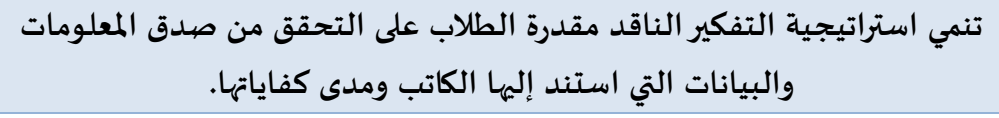 & 9 \\
\hline 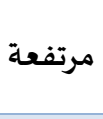 & 8 & 0.49 & 4.34 & تنمي مهارة التفكير الناقد مقدرة الطلاب على التمييز بين المعلومات ذات الصلة & 10 \\
\hline 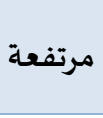 & 9 & 0.99 & 4.31 & تنمي استراتيجية التفكير الناقد مقدرة الطلاب على استخلاص الأفكار الرئيسة & 12 \\
\hline 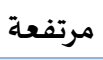 & 10 & 0.90 & 4.29 & تنمي استراتيجية التفكير الناقد مهارة تفسير وفهم المادة المقروءة. & 13 \\
\hline 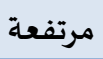 & 11 & 0.79 & 4.28 & تنمي استراتيجية التفكير الناقد مهارة ربط الأفكار مع بعضها البعض. & 11 \\
\hline 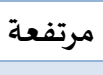 & 12 & 0.75 & 4.25 & تنمي استراتيجية التفكير الناقد مقدرة الطلاب على التنبؤ بالأحداث. & 15 \\
\hline 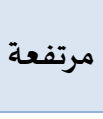 & 13 & 0.76 & 4.21 & تنمي استراتيجية التفكير الناقد مقدرة الطلاب على إعادة صياغة المعاني والأفكار & 3 \\
\hline 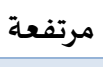 & 14 & 0.85 & 4.19 & تنمي استراتيجية التفكير الناقد مهارة القراءة الاستيعابية. & 4 \\
\hline 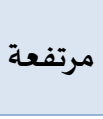 & 15 & 0.94 & 4.15 & تنمي استراتيجية التفكير الناقد المقدرة على تحديد العلاقة بين العبارات & 7 \\
\hline 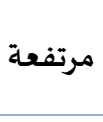 & 16 & 1.12 & 4.12 & 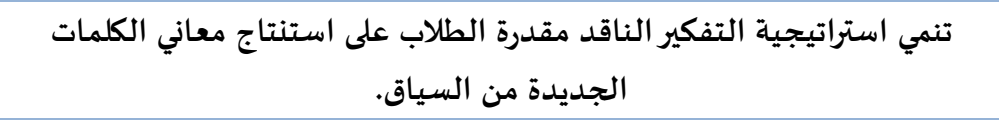 & 17 \\
\hline
\end{tabular}

أثر استراتيجية التفكير الناقد في تنمية المهارات القرائية

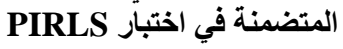


تقوم على تنشيط عقل الطالب وزيادة فاعليته لفهم النص المقروء وتحليله وتركيبه والحكم عليه، إضافة إلى طرح الطالب للعديد من الأسئلة التي ترتبط بالمقروء ومراقبته لفهماه، وتساعد الطالب على عمل ارتباطات بين معارفه

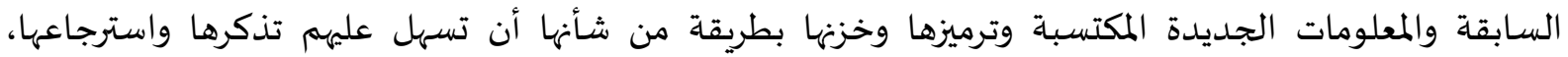
وتتضمن هذه العملية الفهم والتطبيق والتحليل والتقويم. وقد اتفقت هذه النتيجة مع دراسة عيسى (2018) ودراسة الحوامدة (2015).

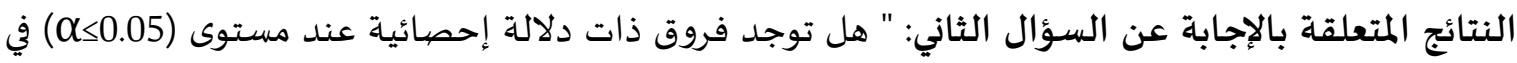

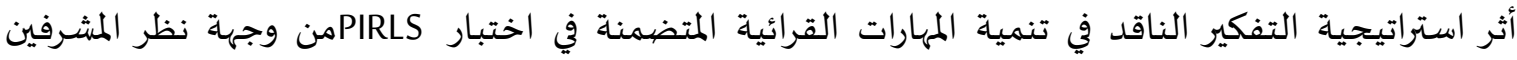
التربويين في محافظتي جرش وعجلون تعزى لمتغيري (الجنس، والمديرية)؟

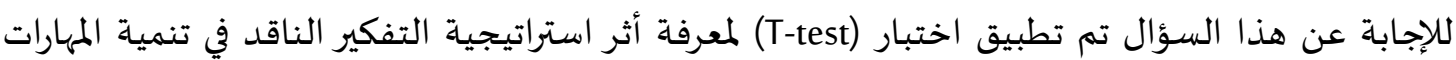

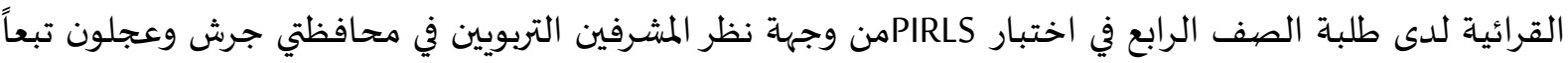
لمتغير: الجنس: (ذكر، أنثى)، ومتغير المديرية (عجلون، جرش) والجدول (7) يبين تلك القيم. الجدول (7): نتائج تطبيق اختبار (t-test) تبعا لمتغير الجنس والمديرية

\begin{tabular}{|c|c|c|c|c|c|}
\hline الدلالة & درجات الحربة & قيمة T T & المتوسط الحسابي & فئة المتغير & المتغير \\
\hline \multirow{2}{*}{0.136} & \multirow{2}{*}{80} & \multirow{2}{*}{1.50} & 4.42 & ذكر & \multirow{2}{*}{ الجنس } \\
\hline & & & 4.22 & أنثى & \\
\hline \multirow{2}{*}{0.075} & \multirow{2}{*}{80} & \multirow{2}{*}{2.76} & 4.25 & عجلون & \multirow{2}{*}{ المديرية } \\
\hline & & & 4.39 & جرش & \\
\hline
\end{tabular}

يتضح من الجدول (7) عدم وجود فروق ذات دلالة إحصائية عند مستوى (1<0.05) في مستوى أثر

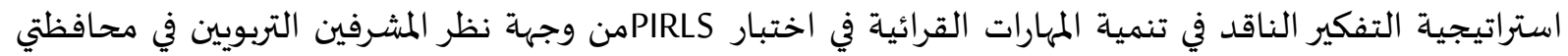

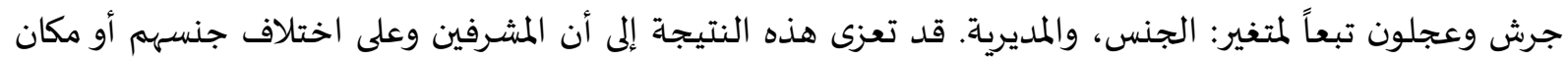

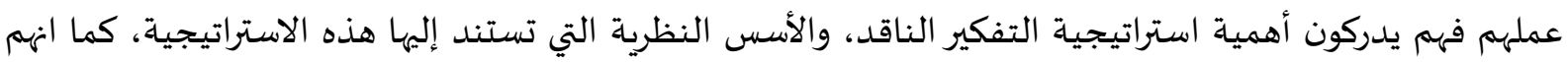

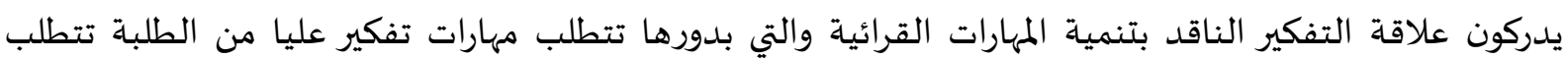

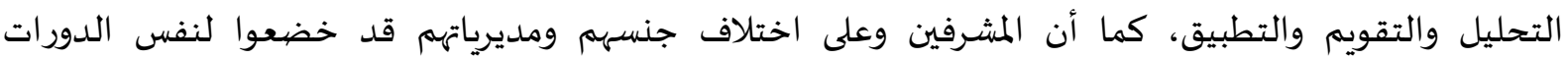
التدربية والمتعلقة باستراتيجيات التدريس الحديثة.

الاستنتاجات:

$$
\text { أظهرت نتائج الدراسة ما يلي: }
$$

1- أن دور استراتيجية التفكير الناقد في تنمية المهارات القرائية المتضمنة في اختبار

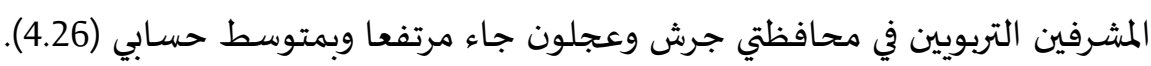
2- كان حجم الأثر لاستراتيجية التفكير الناقد في تنمية المهارات القرائية المتضمنة فئسئ في اختبار

3- عدم وجود فروق ذات إحصائية في مستوى أثر استراتيجية التفكير الناقد في تنمية المهارات القرائية

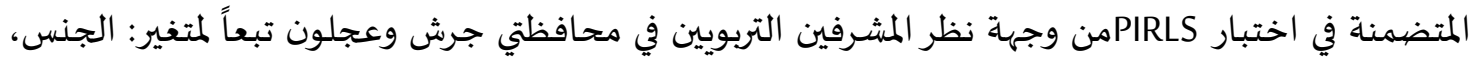

$$
\text { والمديرية. }
$$


يرى الباحث أن أثر استراتيجية التفكير الناقد في تنمية المهارات القرائية الايجابي، يرجع إلى كونهما عمليتين

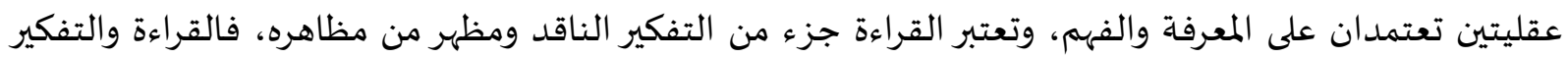
الناقد عمليتان متلازمتان تركزان على استخدام المهارات العقلية العليا، والتفكير الناقد يتمثل في إصديدار المدار القرارات

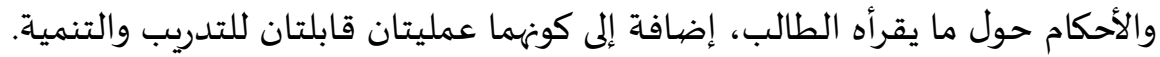

$$
\text { التوصيات والمقترحات. }
$$

1- توظيف استراتيجيات التفكير الناقد في تدريس اللغة العربية بفروعها المختلفة لتنمية مهارات العبية لدى

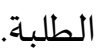

2- عقد دورات تدرببية تستهدف تدريب معلمي اللغة العربية على كيفية توظيف استراتيجيات التفكير الناقد في دروس القراءة وآليات تفعيلها.

3- ضرورة اهتمام المشرفين التربويين بخلق بيئات تعلم نشطة للطلبة من خلال حث المعلمين على استخدام

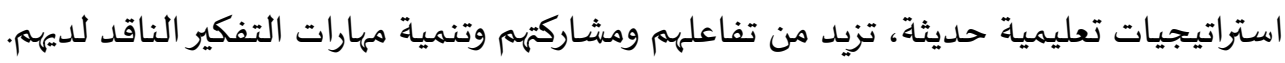

قائمة المراجع.

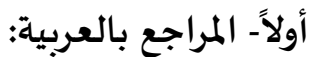

- - إسماعيل، زكريا (1999). حرف تدريس اللغة العربية. ط1. دار المعرفة الجامعية. الإسكندرية.

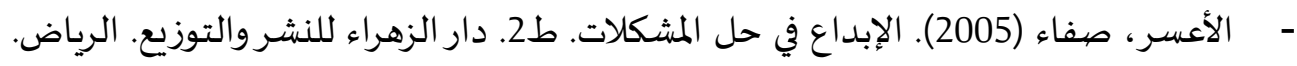

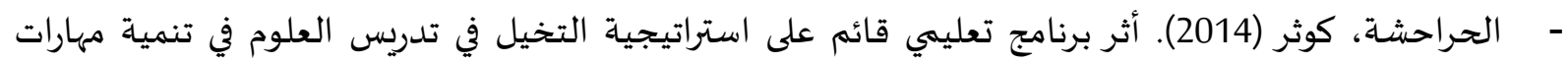

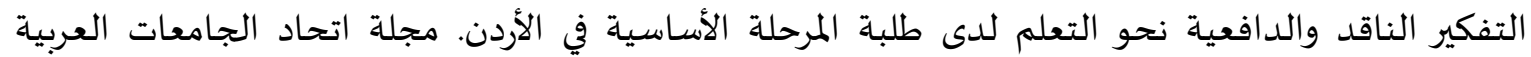
للتربية وعلم النفس. 12 (1). 188-221. - الحسامي، عبد القوي (2012). استراتيجيات التفكير الناقد التي يستخدمها معلمي اللغة العربية في تدريس المفاهيم النحوية. متوفر على:www.monshawi.com - حميد، رائدة (2017). أثر استراتيجية التعليم التعاوني في اكتساب المفاهيم النحوية وتنمية مهارات التفكير

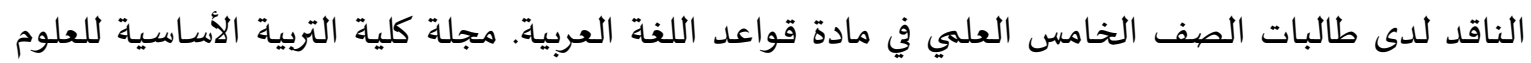
التربوية والإنسانية. العدد (32). 549-577.

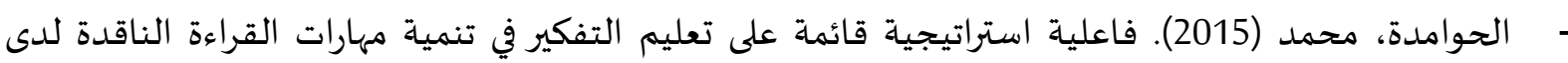

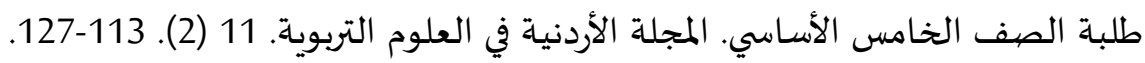

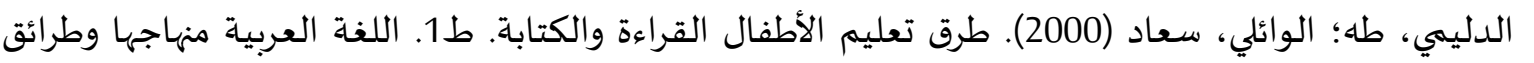
تدريسها. دار الشروق للنشر والتوزيع. عمان-الأردن. زايد، فهد الخليل (2006). تدريس اللغة العربية بين المهارة والصعوبات. ط1. دار اليازوري العلمية. عمانالأردن. - السليتي، فراس (2020). فاعلية برنامج قائم على استراتيجية الجدول الذاتي في تنمية مهارات القراءة الناقدة لدى طلبة الصف الأول الثانوي واتجاهاتهم نحوها. مجلة دراسات العلوم التربوية. 37 (3). 372-395.

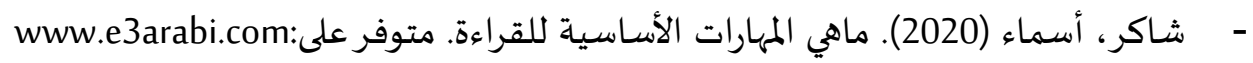


- الشلاش، عمر (2017). أثر استخدام بعض استراتيجيات التفكير ما وراء المعرفي في مستوى التفكير الناقد والثقة بالنفس لدى طلبة جامعة شقراء. مجلة كلية التربية السياسية للعلوم التربوية والإنسانية. 36. 173-200.

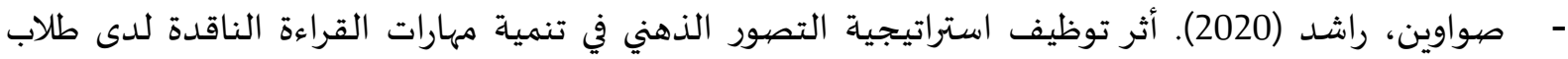

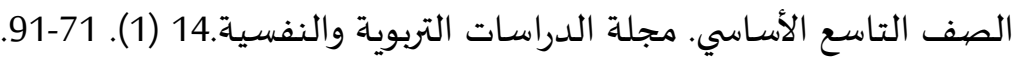

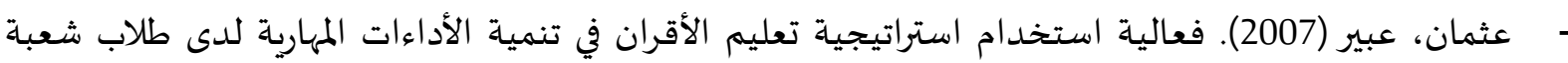

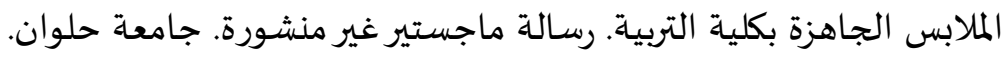

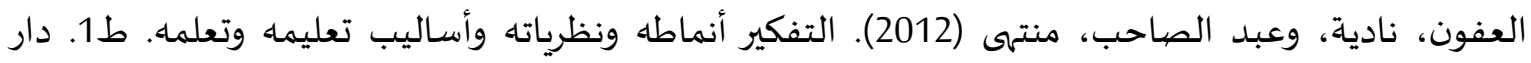
صفاء للنشر والتوزيع. علان، علا موسى (2019). فاعلية استخدام القصة الرقمية في تنمية مهارات القراءة الجهرية في مادة اللغة

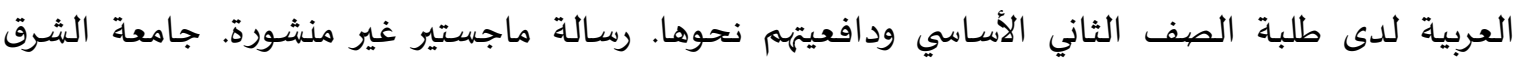
الأوسط.

عيسى، وجدان (2018). أثر استخدام استراتيجيات التفكير المتشعب في تنمية مهارات الفهم القرائي لدى تلميذات الصف الرابع الأسـاسي. رسالة ماجستير غير منشورة. الجامعة الإسلامية بغزة التهات. الكحالي، سالم (2010). صعوبات تعلم القراءة تشخيصها وعلاجها. مكتبة الفلاح للنشر والتوزيع. مركز البحوث والدراسات متعددة التخصصات (2021). التفكير الناقد- تعريفه وتصنيفها ومهاراته وطرق تنميته. متوفر على:www.mdrscenter.com

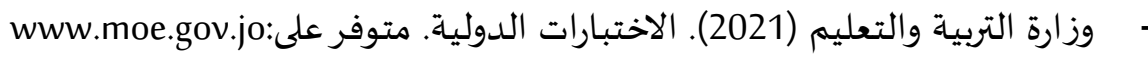
ثانياً- المراجع بالإنجليزية:

- Desanit, K (2011). Report on the Visual Thinking strategies implementing and assessment. Project at Bingham Memorial school, Cornwall, Vermont. Copyright Visual thinking strategies Vts home. Org.

- Durukan, F (2011). Effects of cooperative Integrated reading and Composition (CIRC) technique on reading writing skill. ERIC, EJ1923632.

- Indah, M (2018). The use of (K.W.L) strategy to improve students reading skill in descriptive text for the 8th grade students of SMPN1 pecangaan Jebra in Academic year 2017-2018. English Linguistic research. 9 (1): 86-98. 